San Jose State University

SJSU ScholarWorks

Master's Theses

Master's Theses and Graduate Research

Spring 2017

\title{
Affective and Cognitive Effects of Awe in Predicting Hopelessness and Brooding Rumination
}

\author{
Eldita Tarani \\ San Jose State University
}

Follow this and additional works at: https://scholarworks.sjsu.edu/etd_theses

\section{Recommended Citation}

Tarani, Eldita, "Affective and Cognitive Effects of Awe in Predicting Hopelessness and Brooding Rumination" (2017). Master's Theses. 4824. DOI: https://doi.org/10.31979/etd.v6td-4d7s

https://scholarworks.sjsu.edu/etd_theses/4824

This Thesis is brought to you for free and open access by the Master's Theses and Graduate Research at SJSU ScholarWorks. It has been accepted for inclusion in Master's Theses by an authorized administrator of SJSU ScholarWorks. For more information, please contact scholarworks@sjsu.edu. 


\title{
AFFECTIVE AND COGNITIVE EFFECTS OF AWE IN PREDICTING HOPELESSNESS AND BROODING RUMINATION
}

\author{
A Thesis \\ Presented to \\ The Faculty of the Department of Psychology \\ San José State University \\ In Partial Fulfillment \\ of the Requirements for the Degree \\ Master of Arts
}

by

Eldita Tarani

May 2017 
(C) 2017

Eldita Tarani

ALL RIGHTS RESERVED 
The Designated Thesis Committee Approves the Thesis Titled

\section{AFFECTIVE AND COGNITIVE EFFECTS OF AWE IN PREDICTING} HOPELESSNESS AND BROODING RUMINATION

By

Eldita Tarani

APPROVED FOR THE DEPARTMENT OF PSYCHOLOGY

SAN JOSÉ STATE UNIVERSITY

May 2017

Gregory J. Feist, Ph.D. Department of Psychology

Valerie Carr, Ph.D Department of Psychology

Howard Tokunaga, Ph.D. Department of Psychology 


\title{
'ABSTRACT
}

\section{AFFECTIVE AND COGNITIVE EFFECTS OF AWE IN PREDICTING HOPELESSNESS AND BROODING RUMINATION}

\author{
by Eldita Tarani
}

This study investigated the effects of awe, as a positive emotion, in ameliorating depressive symptoms such as hopelessness and rumination. Previous research indicates that awe is unique compared to other positive emotions in that is elicited by information rich-stimuli that facilitate shifts in cognition as one attempts to accommodate this new information to their current frame of reference. In addition, awe was found incite a selfdiminishing effect that contrast the inflated significance one places on the self, during negative self-referential thinking (e.g. hopelessness). We hypothesized that exposure to an awe stimuli (video) would prompt subjects to feel less hopeless than those exposed to an amusing stimuli (video), with amusement as a control. Furthermore, we hypothesized that levels of awe could predict hopelessness above and beyond demographics and neuroticism, a predictor of negative affect. Lastly, we explored if being in the awe condition effects brooding rumination as the tendency to focus on the negative outcomes of a situation. We tested these hypothes is with an online sample $(\mathrm{N}=271)$ and did not find a significant mean difference in hopelessness between conditions, however we did find that being in the awe condition and experiencing higher levels of awe does predict hopelessness beyond neuroticism. Furthermore, we discovered that awe does marginally predict brooding rumination. While strictly experimental research is encouraged to further test these results, the current findings offer evidence that greater experiences of awe are promising predictors of depressive symptoms. 


\section{ACKNOWLEDGMENTS}

I would first like to thank my advisor Dr Greg Feist for tirelessly offering his professionalism as a researcher and a professor, for his enthusiasm for the project and the highly-dedicated support, even when that meant giving advice during academic breaks or holidays. His contribute was crucial to my development as a researcher. Next, I would like to thank my highly-esteemed committee members, Dr Valerie Carr who shared invaluable advice with me, especially with the study design, as well as Dr Howard Tokunaga whose excellent knowledge and experience in statistical analysis and academic projects was crucial to the project. I want to acknowledge and highlight these professor's flexibility with my timeline and their inherent will for the student to succeed. Next I would like to thank from the bottom of my heart my life partner, Valon Badivuku, for a tireless support, motivation and care, and my parents Elmir and Diana Tarani, who helped my formation as a curious individual and planted my love for science with the addition of my sisters Dora and Harea. In addition, this journey would not have been as smooth if it weren't for the support of my cohort and friends, Jenna Brennan, Adrian Davis, Preston Brown, Zach Caddick, Roberta Cohrson and Alicia Bogart, Becca Herring and Chris and Beth Crapo who brought me coffee and kept my spirits. Furthermore, I would like to thank the Fulbright Scholarship for the precious opportunity to study at this University, especially Ms Kelly Bonin for her work in managing my scholarship and my education opportunities. Lastly, I would like to thank Ms Alena Filip from the research office, the undisclosed reviewers of this thesis and all other SJSU professors who contributed on my journey to become a master of this degree. 


\section{TABLE OF CONTENTS}

List of Tables..................................................................................................... vii

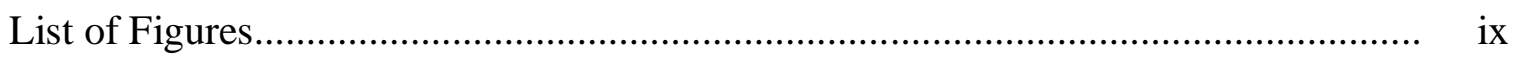

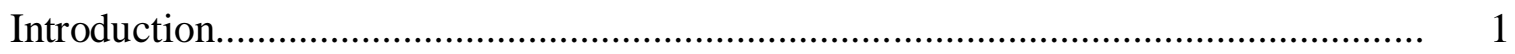

Awe and Dysphoric States: The Present Evidence................................................ 2

Self-Referential Negative Thinking, Hopelessness and Control............................... 4

What it Means to Experience Awe? ……………………………………………... 5

The Smallness of Self.......................................................................................... 6

Awe and Cognitive Organization........................................................................ 7

Ruminative Tendencies................................................................................ 8

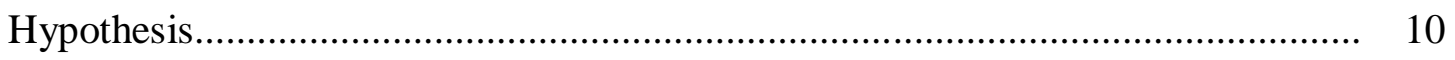

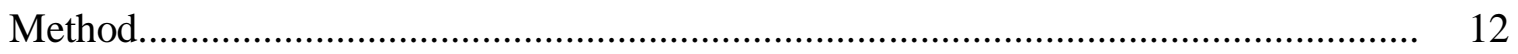

Participants......................................................................................... 12

Measures for Reliability of Responses....................................................... 13

Apparatus and Materials...................................................................... 14

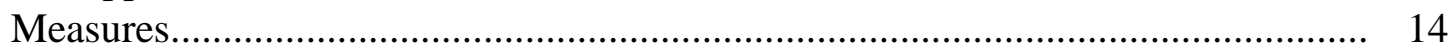

Instructions..................................................................................... 14

Depression, Anxiety and Stress Scale - 21 item version (DASS-21)................ 14

The Big Five Inventory - 10 items............................................................... 16

Awe-Induction................................................................................ 16

Amusement Video.................................................................................... 17

Instruction Manipulation Check Questions...................................................... 18

Emotion Manipulation Check Questions......................................................... 19

State/Trait Hopelessness Scale..................................................................... 19

Ruminative Response Style (RRS)............................................................. 20

Demographics Questionnaire....................................................................... 20

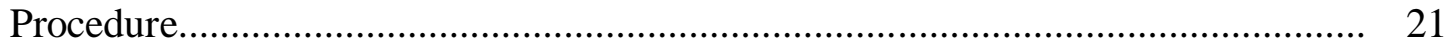

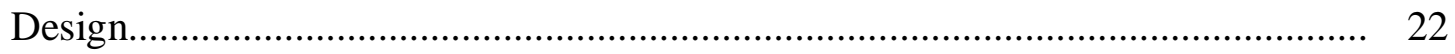

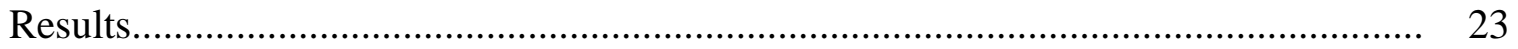

Data Cleaning......................................................................................... 23

Descriptive Statistics..................................................................................... 23

Sample Equivalency................................................................................... 26

Manipulation Check ……………………………………………………... 27

Hypothesis Testing........................................................................................ 28

Hierarchical Multiple Regression Analysis........................................................... 31

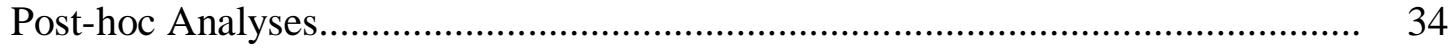

Analyzing Level of Awe as a Moderator......................................................... $\quad 34$ 
Other Post-hoc and Unplanned Analyses............................................. $\quad 35$

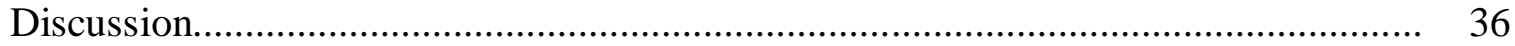

Predicting Brooding Rumination................................................................ 37

Awe and Nature................................................................................ 38

Level of Awe as a Moderator..................................................................... 39

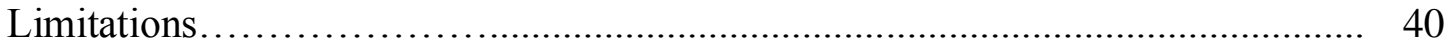

Implications and Future Directions...................................................... 41

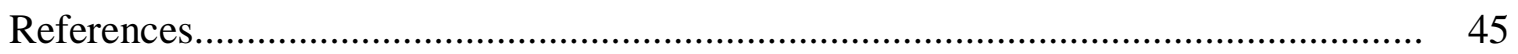

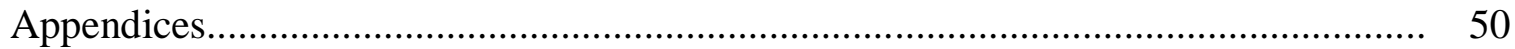

Appendix A: The Consent Form/Introduction............................................... 50

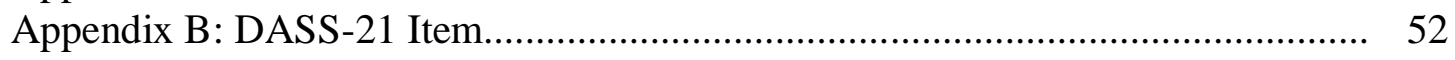

Appendix C: BFI-10 Item......................................................................... 54

Appendix D: Awe Video, Instructions and IMC's.......................................... 55

Appendix E: Amusement Video, Instructions and IMC's................................ 56

Appendix F: Emotion Manipulation Check................................................ 57

Appendix G: The State/Trait Hopelessness Scale........................................... 58

Appendix H: Ruminative Response Scale................................................. 59

Appendix I: The Demographic Questionnaire .............................................. 60

Appendix J: Conclusion of the Survey and Payment Instructions........................ 62 


\section{LIST OF TABLES}

Table 1. Descriptive Statistics................................................................... 26

Table 2. Group Differences by Condition....................................................... 27

Table 3. Manipulation Check Results..................................................................... 29

Table 4. Comparing Awe and Amusement on Hopelessness and Rumination......... $\quad 30$

Table 5. Pearson (r) Hopelessness-Condition and Rumination-Condition Correlations (subscales)................................................................... 31

Table 6. $\quad$ Pearson (r) Correlations Between MRC Variables.................................... 32

Table 7. Hierarchical MRC: Demographic and Ideological and Psychological Predictors of Total Valid Reasoning............................................................ 33

Table 8. Hierarchical MRC: Demographic and Ideological and Psychological Predictors of Total Invalid Reasoning.... 


\section{LIST OF FIGURES}

Figure 1. Sitemap of the Experiment as Viewed by the Participants in Qualtrics..... 


\section{Introduction}

The increase of human consciousness regarding well-being has brought the realization that nurturing compassion for oneself and others sits at the center of ideal human experience. Because compassion is mainly associated with positive emotion, a new wave to understand positive emotion both as a cause and as an effect of other mental states has emerged. As a result, many scientists interested in mental well-being focus on understanding the facilitators and effects of positive emotions as the central premise of their research. It seems this trend has increased since research uncovered that certain positive emotions hold properties that display a clear ability to predict change not only in a person's mood but also in the way they think and interpret reality (Fredrickson, 2001; Isen, 2000).

Recent research suggests that a specific emotion befitting these criteria is the positive emotion known as awe. As a positive affective state, awe stands out as a positively valenced emotional response to a stimulus that is information-rich in nature (Keltner \& Haidt, 2003; Shiota, Keltner \& Mossman, 2007) and as a result, motivates the individual to revise and re-appraise his or her existing frames of knowledge. Besides that, experiencing awe is associated with deflecting attention from the self as it is rarely elicited by self-relevant elicitors (Shiota et al., 2007).

In contrast to the effects of this positive affective experience, depressive states involve inward negative self-referential evaluations associated with one's worthlessness or helplessness (Beevers, Disner, Haigh \& Beck, 2011). Furthermore, such affective states are associated with counterproductive ruminative tendencies that sustain the experiencing of the negative affect, most likely by letting mood affect cognition (Nolen-Hoeksema, 1991; Whitmer, \& Gotlib, 2013). This is especially true 
if we consider the research of Nolen-Hoeksema and colleagues (2011), which shows that the duration of depressive symptoms is considerably defined by the way individuals respond to them. This contrasting logic drove us to investigate whether awe as an emotion with the potential to induce a revision of one's current frame of reference and lessen self-focus could predict lower dysphoric mood above and beyond personality variables and its positive emotional valence. Although rarely studied in this context, a modest body of research provides evidence that links awe to wellbeing.

\section{Awe and Dysphoric States: The Present Evidence}

Negative affect predicts worse physical and mental well-being (Alper \& Skoner, 2003; Cohen, Doyle, Turner, Davidson, 2004; Ryff, Singer, \& Dienberg, 2004; Watson, \& Pennebaker, 1989). One of the explanations for this finding relates to the increase of pro-inflammatory cytokines whose persisting existence in the absence of an illness presents harm to health (Kiecolt-Glaser, McGuire, Robles \& Glaser, 2002). A study conducted by Stellar and colleagues (2015) showed that awe was the strongest predictor from seven positive emotions to predict lower levels of the proinflammatory cytokines (Stellar, Anderson, Gordon, Mcneil \& Keltner, 2015). Furthermore, these researchers found that the more (state) awe the participants experienced in the day of the experiment, the lower their levels of the proinflammatory cytokine Interleukin-6 present. This was true even after controlling for personality variables and health factors. The authors speculated that the outcome may be related to awe's effect of leaving the individual feeling a sense of interconnectedness. 
Another study associated awe with the lengthening of the cardiac pre-ejection period (PEP). Levels of PEP determine the reactivity of the sympathetic nervous system which has been associated cardiovascular arousal, contrary to the parasympathetic nervous system (Musser, Backs, Schmitt, Ablow, Measelle, \& Nigg, 2011). An increased sympathetic nervous system is characterized by shorter values of PEP, whereas longer PEP indicates a decelerated heart rate and sympathetic withdrawal which in core means increased parasympathetic activity (Shiota, Neufeld, Yeung, Moser \& Perea, 2011). A limited body of literature shows that the dispositional experience of positive affect was associated with a reduction in cardiovascular arousal, as a measure of sympathetic nervous system activity (McCraty, Atkinson, Tiller, Rein \& Watkins, 1995). In a study of positive emotions and the autonomous nervous system, Shiota and colleagues (2011) hypothesized that awe may predict withdrawal of the sympathetic influence and found that the lengthening of the PEP was indeed associated with the awe condition. In agreement with these findings, Demaree, Schmeichel, Robinson, and Everhart (2004) have suggested that sympathetic withdrawal can be a product of an intense cognitive effort. In addition, because awe is elicited by stimuli that are vast in nature and tend to overwhelm cognitive capacities (Shiota et al., 2007) caused by the need to accommodate that very novel sensory information, we can deduce how awe can be related to sympathetic withdrawal. This evidence supports the assumption that awe precedes a relaxed and more mindful state, which contrasts that characterized by worrying associated with negative self-reference and brooding rumination which results in one feeling hopeless. We set out to further explore factors that associate awe with a change in these dysphoric tendencies. We believed that understanding factors 
associated with this assumption would help uncover awe's potential for clinical applications apart from the scientific implications. One clinical application would be awe's association with depression and hopelessness.

\section{Self-Referential Negative Thinking, Hopelessness and Control}

Self-referential negative thinking is one of the leading proponents of depressive mood (Zahn, Lythe, Gethin, Green, William, Young, \& Moll, 2015). Depressive tendencies usually result from erroneous expectancies that one should be in total control of his or her reality which results with an over-generalized self-blame once the complete control proves to be impossible (Green, Moll, Deakin, Hulleman \& Zahn, 2013). For example, Green and colleagues (2013) found that an increased selfcontempt bias (inclusive of self-blame) was characteristic of subjects with remitted major depressive disorder (MDD) in contrast to a reduction of such bias towards others. On the other hand, Zahn and colleagues (2015) found these negative selfreferential and self-blaming conceptualizations presented the core of depressive syndrome and were associated with hopelessness. Similarly, another cognitive model based on the works of Abramson, Metalsky, \& Alloy (1989) known as the hopelessness theory of depression, attributes the core of depressive states to an inferential type of thinking style which appraises negative events as occurrences resulting from one seeing themselves as a failure and as not having any prospect to avoid further negative outcomes that will arise from that event. This illustrates two aspects that are problematic: the individual feeling helpless and hopeless (NolenHoeksema, Wisco, \& Lyubomirsky, 2008). Per such theory, hopelessness was defined as one's repeated expectation of not having control over occurrences of a highly-

wanted outcome, replaced by expectancies of highly aversive occurrences (Metalsky 
\& Joiner, 1992). Additionally, the theory posits that the individual is biased to feel as if there is nothing they can do to change the situation once the undesired outcome has occurred, as per their expectation. According to Nolen-Hoeksema et al., (2008), it is this kind of repeated reflective processing that characterizes depression where the individual will focus on all the negative events relevant to him/her and note a sense of hopelessness across them. We believe that experiencing awe, might promote less selfreferential thinking caused by the re-appraisal of the meaning of control given that awe is shown to promote the sense of smallness of self and the view that there are grander things at play out there (Piff, Dietze, Feinberg, Stancato \& Keltner, 2015; Shiota, et al., 2007; Silvia, Fayn, Nusbaum, \& Beaty, 2015). Similarly, an aweinspired individual is likely to undergo a process of the revision of his or her current knowledge and comprehension schemas as a result of the process of accommodation of the new information they find themselves upon (Shiota et al., 2007), given that the stimuli is truly awe-inspiring to them.

\section{What it Means to Experience Awe?}

The scientific study of awe required taking a leap from a conventional and prototypical view of positive emotions to another level of analysis and using definitions from cognitive psychology. Psychologists explored awe under labels such as wonder, admiration or peak experience (Keltner \& Haidt, 2003). One of the early well-known psychologists, McDougall (1910) saw awe as a state closely related to admiration but with an undefined emotional valence. Similarly, Maslow (1964) discussed it as a peak experience with transcendental and change-inspiring properties. In summation, these theoretical attempts found agreement between scientists when awe started to be seen as a pleasant emotional state evoked by the presence of a vast 
cognitive and sensory experience that required some kind of cognitive accommodation and created a sense of the self being insignificant (Keltner \& Haidt, 2003). Further, we discuss in more detail the unique and research-based characteristics of this emotion that set it aside as and possibly award it the power to predict the decrease of dysphoric states.

\section{The Smallness of Self}

We reiterated many times that awe possesses some special qualities that set it aside as a positive emotion. One aspect that sets it apart from other positive emotions is its observed asocial nature (Piff et al., 2015; Shiota et al., 2007). Researchers found that during the experience of awe, when a hypothesized shift in cognition took place, subjects reported thinking of themselves in terms of universals (Piff et al., 2015; Shiota et al. 2007). Thinking of oneself in terms of belonging to universal categories (e.g. human, inhabitant of the world, etc.) does indeed shift the emphasis of oneself to something greater, something unifying. Thus, many awe researchers argue that a selfdiminishing effect is created by the experience of awe and as a result it promotes a sense of smallness of self (Piff, Dietze, Feinberg, Stancato \& Keltner, 2015; Shiota, et al., 2007; Silvia, et al., 2015). This is not surprising when we recount that awe is usually felt and described in terms of religious, spiritual and transcendental experiences (Keltner \& Haidt, 2003). As discussed earlier, such an effect could help the individual focus less on the negative self-reflecting behavior.

Aside from this finding, Piff and colleagues (2015) observed that awe increased pro-social values, which lowered the feeling of entitlement. They further found that this change was mediated by the subject's perception that there are things greater than the self. Due to this finding, we believe that one's worries and concerns should feel 
relatively insignificant when an individual is face-to-face with this vast stimuli. Lastly, a study that examined differences in positive emotions according to their appraisals discovered that participants in the awe condition felt that events were being caused by outside forces rather than the self (Tong, 2015). Ultimately, participants were more likely to see impersonal forces, not themselves being in control. These findings led us to expect that when subjects find themselves in an awe-inspired state, they will tend to perceive their current worries and concerns with less gravity and significance, especially if those are persistent symptoms.

\section{Awe and Cognitive Organization}

Cognition is influenced by positive emotion. Emotion, along with some other aspects relevant to the individual (e.g., their goals and expectations), influences what the person thinks and how they will behave (Isen, 2000). Within a growing body of research on awe, there have been indications that awe influences cognition and as such, presents a potential mechanism that explains awe's role in promoting wellbeing. For instance, Rudd and colleagues (2012) found that awe has the ability to alter the subjective perception of time that influences decision making and well-being. They observed that participants in an awe condition felt they had a greater availability of time. As past work indicates, the perception of elongated time is associated with the perception that we are living in the present moment (Vohs \& Schmeichel, 2003). It is therefore possible that awe causes people to feel they are living in the present moment. To make the connection with our hypothesis, we consider how living in the moment is an important predictor of well-being (Brown \& Ryan, 2003; Christie, Atkins \& Donald, 2016). As such, it is used as a tool in therapeutic practices for 
preventing suicidal behavior (Hayes, Follette, \& Linehan, 2004; Williams, Duggan, Crane \& Fennell, 2006).

Another way in which awe may influence cognition could be attributed to the abundance of sensory information that its elicitors present. Awe is referred to as a subjectively positive, knowledge-based emotion (Tong, 2015). Cognitive appraisals of awe (e.g., need for accommodation) are a good indicator of their information-rich nature. Because the individual does not possess the previous knowledge schema to process that sensory information, a need for the accommodation of the new information is created (Shiota, 2007). Ultimately, the individual faces the prospect of creating informational resources rather than by having to focus on social gains which require that they compare the self to the norm or other people (Piff, 2015; Shiota 2007, 2011). Instead, awe draws the attention from the self and engages the individual in grasping this new vast-stimuli which is fascinating and prompts them to accommodate their knowledge schemas.

\section{Ruminative Tendencies}

It appears that self-reflection is a characteristic behavior of human beings. While it could set us apart as more conscious species, we find that self-reflection is also present in a maladaptive form. Such a more maladaptive form of self-reflection, characterized by repetitive thinking about one's distress and its cause, is defined by a leading author on the topic as a ruminative response (Nolen-Hoeksema, 1991; NolenHoeksema \& Wisco \& Lyubomirsky, 2008). In this paper, we will simply refer to it as rumination. According to Nolen-Hoeksema et al., (2008) by ruminating, a person does not reach any solution to the problem or the cause of the distress because such thinking style is not constructive and not focused on problem solving, therefore not 
followed by targeted action. Instead, they remain passive and impulsively think of the problem and as a result, experience negative feelings associated with it. According to Nolen-Hoeksema (1991), this may be the case due to a created sense of hopelessness that pushes the individual to obsessively focus on the barriers that prevent them from finding solutions.

These definitions are especially true for brooding rumination, a concept that derived from the factor analysis of the Ruminative Response Scale (Treynor \& NolenHoeksema, 2013). Out of the two rumination factors that distinguished this scale, brooding rumination was defined as a measure of a more maladaptive type of rumination, characterized by negative-self-reflection and a focus on self-blame. The other factor, labeled as the reflective rumination was less correlated with depression and depicted a general self-reflective tendency (Nolen-Hoeksema, et al., 2008). Additionally, there is evidence that suggests that a brooding ruminative thinking style is responsible for the retrieval of negatively biased self-schemes (Schneider \& Brassen, 2016) by interfering with the search for specific memories. It is possible that experiencing awe might somehow restrict this mechanism such that the individual displaces the focus from the retrieval of the negatively biased information or focuses simply engages all cognitive effort in understanding the new information-rich stimulus.

Given that our interest is to understand the effects of awe as they impact these negative, repetitive self-referential tendencies, we analyzed brooding rumination as an outcome variable and included the concept in one of our hypothesis.

Due to a lack of evidence that correlates awe as a positive emotion with rumination, we could not hypothesize confidently enough that awe will have an 
impact in negative rumination. Our hypothesis, therefore, was based more in logic. Rationally, awe should direct individual's attention towards extrinsic factors, moving the focus from self-referential thinking to more collective and vast issues. Hence, we argued that awe will affect brooding rumination, and by doing so we hope to create grounds for further research on the topic.

\section{Hypotheses}

In consideration to the research we discussed here, we set out to test the assumption that awe, as a positive emotion but beyond that as an emotion shown to challenge the frame of reference and create a shift in cognition, would predict a decrease in negative affect, namely hopelessness. To test this, we looked at the difference between awe and amusement as a contrasting emotion, known to induce feelings of pleasantness and general positivity. We choose amusement specifically because it was used in a similar context before and as such found to be reliably induced using video clips (e.g., Algoe \& Haidt, 2009; Valdesolo \& Graham, 2014, 2014). Previous researchers like Valdesolo and colleagues (2014) found amusement to be a good contrasting emotion to awe because while it is positively valenced, but beyond that it did no present any evidence that it would induce cognition-related effects in the individual such as overwhelming cognitive capacities and creating the need for accommodation.

We expect that there will be a negative relationship between awe and hopelessness, and this relationship will be stronger than the relationship between amusement and hopelessness. Additionally, higher levels of awe will be associated with lower hopelessness, even after demographics and neuroticism are held constant. We want to hold demographics (age and gender) and neuroticism constant so we can 
rule them out as possible explanations of hopelessness. We included the personality measure of neuroticism in our analysis as a control, given that it is a reliable indicator of one's predisposition of experiencing negative affect (Widiger, 2009) and therefore will allow us to establish the effect of awe, even if we have accounted for the fact that some individuals are more prone to negative affect despite extrinsic factors than others. In addition, the more awe the individual has experienced, the more his or her frame of reference has been accommodated to accept new and unexplored possibilities in their life and their future, therefore ensuring a more hopeful attitude towards the outcomes of their lives. Through a series of experiments, we will test the following hypotheses:

H1-a) Participants who experience awe (the awe video condition) will experience less hopelessness compared to those who are in another positive emotion condition (amusement group). Therefore, we hypothesize that experiencing the positive emotion of awe will decrease one's feelings of self-referential hopelessness.

H1-b) The awe video condition will be negatively correlated with hopelessness.

H2) Higher levels of awe will predict lower hopelessness even once gender, age, and the personality dimension of neuroticism are controlled for.

H3) Higher levels of awe experience will predict lower brooding rumination score.

With a rich dataset, we set out to answer some exploratory questions such as how would strongly is the level of awe experienced associated with one's feeling that there is something greater out there. Similarly, we planned to look at the correlation 
between levels of awe and how much did the participants find the images in the awe induction video to challenge their current frame of reference (post-hoc analysis).

\section{Method}

\section{Participants}

Participants were recruited via Amazon's Mechanical Turk (MTurk) to participate in an online study, known to the MTurk community as a human intelligence task (HIT), via a solicitation post that appeared on the MTurk website. From a total of 292 respondents who took the survey, 271 completed it fully. The rest quit the browser before completion or were screened-out for failing the video attention check. A small compensation of $\$ 1.25$ was offered to those who complete all the phases of the experiment and a smaller fee of $\$ .45$ was offered for partial participation. This fee constituted the main known motive for participation. Each participant had to read a consent page (see Appendix A). Participants could only access the study if they clicked "I agree" to the statement "I have read and agree to participate in this study."

We employed two criteria to allow for participation. One required that the respondents live in the U.S., which would offer some assurance that they speak fluent English as well as to avoid any cultural differences that might act as nuisance variables. The other criterion required respondents to have had at least a $97 \%$ successful approval rate of previous HITs they had worked on. This was necessary to ensure that participants were reliable respondents and that their previous work as participants was not rejected for ethical, attentional or completion issues.

With the technological advancements and emerging new media, MTurk (www.mturk.com) has become a rather popular choice for research projects, especially those with larger sample sizes. We used it as an intermediary medium to 
help us recruit and compensate the participants for the study. As such, it enabled us to collect data from a large pool of adult participants from a non-college population while addressing the popular concerns about the limited generalizability of a Western Educated International Rich and Democratic, referred to as the "WEIRD" sample (Henrich, Heine, Norenzayan, 2010).

Nevertheless, we noted some concerns in regards to the use of an online subject pool for scientific studies, mainly in relation to the data validity contingent upon whether participants pay attention to the required tasks in such studies. Upon consulting the available literature, we found suggestions that using MTurk workers as participants is likely to produce valid results when manipulation check techniques are employed (Oppenheimer \& Davidenko, 2009). These techniques are referred to as instructional manipulation checks (IMCs) and are found particularly effective in ensuring that the participants are paying attention to the task or questionnaire administered. In three studies, Oppenheimer and Davidenko (2009) found that MTurk workers (respondents) were more attentive to the task than a sample of classic university students, making this a credible choice of subjects (Goodman, Cryder, \& Cheema, 2014).

Measures for Reliability of Responses. To reduce the possibility of invalid responses, we enforced different online administration control measures. One measure we took to ensure validity was breaking down the data collection phase. Instead of collecting all of the responses within a day, we launched the survey in batches of nine participants at a time over three days. This helped prevent regular MTurkers from sharing study related information in MTurk social forums, especially the answers to the attention checks. Another measure was including a verification code which is a 
simple challenge test known as the "Completely Automated Public Turing test to tell Computers and Humans Apart" (CAPTCHA) that is used to tell if the responses are coming from pre-programed software robots or humans. Additionally, we included a screening out procedure based on age (under 18) and the passing of attention check questions. Finally, the incentive of the partial compensation helped filter unmotivated participants who were not dedicated to the study but rather just interested in the reward. Participants who quit the survey before the video task were still compensated accordingly.

Apparatus and Materials. The online study was developed and administered using the Qualtrics software (Qualtrics, Provo, UT). Participants were referred to Qualtrics from the MTurk website/platform where we posted a solicitation for this study.

\section{Measures}

Instructions. Study instructions were outlined in the first page of the study, which also served as a consent form. There, we told the participants that they were going to participate in an experiment about nature and cognition, to avoid any bias in the answers. Next, we described the procedure of the study in detail, reiterating how undivided attention to the tasks and survey was crucial to the study. We also included information about IMC's screen-out procedure. In the end, the participants were asked to agree to participate if they wished to do so, but only if they were older than 18 years of age.

Depression, Anxiety and Stress Scale - 21 item version (DASS-21). We used the DASS based on recommendations from previous studies, which found the instrument to be an excellent and valid method for measuring the presence of 
depressive symptoms, anxiety and stress in both clinical and non-clinical sample groups (Antony, Bieling, Cox, Enns, \& Swinson, 1998; Lovingbond \& Lovingbond, 1995). To be pragmatic, in the interest of time we chose to administer the shorter version comprised of 21 items. This version of the DASS presents a self-report measure consisting of 21 statements rated on a 4-point Likert rating scale (" $0=$ Did not apply to me at all" to " 3 = Applied to me very much or most of the time"). Summed scores are multiplied by two and those on the range of 0-9 indicate an absence of depressive symptoms while anything above that denotes the presence of more heightened depression (see Appendix B).

To obtain the DASS-21 score, scores on each dimension were summed and the subscale scores computed. The 21-item version of the scale has been documented to employ a reliable three-dimensional factor structure: depression symptoms, anxiety or hyperarousal, and stress. Anthony (1998) and colleagues suggested that curtailing the inventory from 42 to 21 items did not cause any damage to the factor structure, explaining further that the reduction of items worked in favor of the shorter version which displayed higher mean loading in factors and fewer between-factor intercorrelations. DASS-21 items have also demonstrated good reliability with a high internal consistency for all three subscales: Depression $(\alpha=.97)$, Anxiety $(\alpha=.87)$ and Stress $(\alpha=.91)$ (Anthony, et al., 1998)

Concurrent validity was examined by other studies that correlated DASS-21 with the Beck Depression Inventory (Beck, Steer, \& Garbin, 1988) for the Depression subscale (DASS-D) where we see a moderately high correlation $(r=.79)$, Beck Anxiety Inventory for Anxiety subscale (DASS-A) where we also can see a moderately high Cronbach's alpha $(r=.84)$, as well as State-Trait Anxiety Inventory 
which is correlated slightly more with DASS-D $(\alpha=.71)$ then DASS-A $(\alpha=.55)$ possibly because the items of the scale assess depressive symptoms as well (Anthony et al., 1998).

The Big Five Inventory - 10 items. As a shorter version of the original Big Five Inventory, the BFI-10 measures five major dimensions of personality (Neuroticism, Extraversion, Openness to Experience, Agreeableness, and Conscientious). It is evident that the instrument can be used, even though only two items rated on a scale from 1-5 (1= "Disagree Strongly", 3= "Neither Agree nor Disagree" and 5= “Disagree Strongly") were used to measure each dimension (see Appendix C). Because we were primarily interested in neuroticism, or one's tendency to experience negative emotions (Widiger, 2009), a shortened version was desired. This shortened version has been constructed for studies with a limited time-frame, but it demonstrates good construct validity (Rammstedt \& John, 2007). The mean correlation between the BFI-10 and the original BFI-44 scales was strong $(r=.83)$ and this is particularly true for the neuroticism dimension $(r=.86)$, whereas test/retest analysis speaks in favor of the reliability of BFI-10 ( $r=.75)$ (Rammstedt \& John, 2003). Additionally, a neuroticism score will help us determine neurotic tendencies, which are found to be related to self-focused referential rumination (Bagby \& Parker 2001).

Awe-Induction. We used a validated video clip to induce awe, our independent variable. Participants were asked to watch a 5-minute video clip from BBC's Planet Earth (see Appendix D for the link to the clip and screenshot images from the video) showing a compilation of vast nature scenes such as mountains, canyons, the earth atmosphere, etc. For added effect, participants were asked to use headphones when viewing it. 
This video segment has been demonstrated to induce awe (Shiota et al., 2007; Valdesolo et al., 2014). For example, Valdesolo and colleagues (2014) administered emotion manipulation checks after they showed it to participants to assess changes in awe and to demonstrate how awe changed people's uncertainty tolerance. They found that the clip did indeed elicit the desired emotion and created the hypothesized effect on uncertainty tolerance (Valdesolo et al., 2014). Evidence from another awe validating induction study found that nature was the most frequent stimulus event with the power to elicit awe in a sample of 60 undergraduate participants (Shiota et al., 2007).

Amusement Video. An amusement video is used to elicit amusement, the contrasting emotion, in our control group. Participants were shown an approximately 4-minute clip from $B B C$ 's comedic series Walk on the Wilde Side involving funny situations with animals naturally occurring in nature (see Appendix E for a description of the video).

Previous research with awe has found amusement to also be a good stimulus for inducing generally positive feelings. Unlike awe, however, amusement does not expand one's frame of reference (Valdesolo et al., 2014). Another differentiating characteristic between awe and amusement is that awe is less social in nature than both happiness and amusement (Shiota et al., 2007). In sum, the video was carefully chosen to elicit amusement, general feelings of happiness and general positivity. An auxiliary advantage it provides is that all of the scenes are shot in nature similar to those in the awe clip, eliminating nature as a factor for explaining our results and enabling us to make inferences beyond it. 
Instruction Manipulation Check Questions. A crucial aspect of this study design involves participants viewing and experiencing the video intended to elicit the corresponding emotion, depending on the condition. A failure to do so would render data invalid. As an assurance that the participants were paying attention to the video, we included four "yes or no" instruction manipulation check questions (IMC) in each condition (e.g. "Did you see any humans in this video") as control measures (see Appendix D and Appendix E). These questions showed up immediately after the viewing of the video. Additionally, to assure that participants were mindfully and conscientiously answering the survey questions and not just randomly selecting answers to move fast within the survey, we included one IMC question when administering each of the following: DASS-21 Items, HPSS and RSS.

IMC's are widely used in online studies, especially in the MTurk world and are useful in determining whether the participant is paying attention to the content of the survey (Oppenheimer \& Davidenko, 2009). We thoughtfully designed these IMC questions with the intention to only measure whether the participants were paying attention to the material. This means that we avoided using wording that would test any other aspect of cognition such as cognitive load, memory, or intelligence. We simply asked the participants to select a "yes" or "no" response that indicated whether they recalled seeing or hearing an "X" object shown in the video, (e.g.,. a human) in the awe clip. Even so, to avoid screening out participants who could have some issues with retaining the content of the video, or simply with hearing, we gave one free pass by adding an extra fourth question while letting them pass if they only got three correct. 
Emotion Manipulation Check Questions. To confirm that awe and amusement were induced, we administered a set of questions immediately following the videos. For example, "How much awe (feelings of overwhelming respect, wonder, admiration and sense of depth) did you experience while watching this video?") (Valdesolo et al. 2014) (see Appendix F).

For the same reason as the IMC's, we included additional five emotion manipulation check questions that used 8-point Likert type rating scale responses (“0 $=$ not at all" to "7 $=$ utmost"). These questions also assessed whether participants experienced concepts related to the definition of awe, such as the feeling of belonging to something greater or whether there is something greater out there. In order to check for amusement, we also asked them if they felt amusement after watching the corresponding videos.

State/Trait Hopelessness Scale. The State/Trait Hopelessness Scale was designed to give an accurate measure of hopelessness as an expectancy of negative outcomes and helplessness, both at a state and trait level (Dunn, Olamijulo, Fuglseth, Holden, Sit, Tintle, 2014) (see Appendix G). As such, the scale measures hopelessness in terms of a cognitive dimension defined by the individual's tendency to interpret life's consequences as negative, and the self-ability to change those situations. Dunn et al. conducted a reliability analysis with a sample of 520 patients, indicating a high reliability for the state subscale $(r=.88)$ as well as the trait subscale $(r=.91)$. Our analyses focused on the state aspect of the scale, referred to as SHS, because we were interested in the state aspect of the manipulation, namely the state of the participants more than their general disposition to experience hopelessness. 
Ruminative Response Style (RRS). Another exploratory outcome measure is rumination, which was assessed with a 22-item questionnaire (Ruminative Response Style) developed by Nolen-Hoeksema (1991) (see Appendix I). The RRS aimed to measure one's ruminative tendencies in negative situations. The rating scale is a 1-4 Likert scale ( 1 = "Almost never" and 4= "Almost always"). These items measure participant's ruminative response style in negative situations by scoring the frequency with which they react in a ruminative way to negative states (i.e. sadness, depression). Higher scores signify a greater tendency to have a ruminative response during these states (Please see appendix $\mathrm{H}$ ). According to various studies, the items of this scale demonstrate a strong internal consistency (Cronbach's $\alpha=.86$ ) and a high reliability in test-retest studies with a time difference of over a year $(r=.47, p<.01)$ (Just \& Alloy,1997; Morrison \& O’Connor 2008; Nolen-Hoeksema \& Morrow, 1991). actor analysis conducted by Treynor and Nolen-Hoeksema (2013) revealed two main factors of interest that distinguished the scale. The brooding factor characteristic of negative self-reflection with the items 5, 10, 13, 15 and16, and the reflection rumination with items $7,11,12,20$, and 21 , characteristic of general reflection. We used all of the scale items for this study since the online format allowed easily to do so, with the goal of exploring how all possible factors could relate to awe.

Demographic Questionnaire. This instrument was designed by the researcher to measure a few demographic variables of interest to the study (Appendix I). The inventory asked participants to indicate their gender, age, ethnicity, level of education and employment status. Such information helps uncover potential correlations between demographic variables, hopelessness and awe. Additionally, we asked participants to indicate categorically how much time they spend in nature. Because 
nature is a strong elicitor of awe (Silvia, et al., 2015), we needed to understand the contribution that exposure to nature makes in explaining variance in hopelessness score.

\section{Procedure}

Participants saw a notification on Mechanical Turk, Amazon's online marketplace for human intelligence tasks inviting them to participate in a study about nature and cognition. To lessen the possibility of bias in the expectations about the experiment, we were discreet and did not use the word "awe" in the title. Once the participant logged into the experiment interface, he or she saw an introductory text explaining the premise of the experiment which also served as the consent form (Appendix J). Here we clearly explained the importance of being attentive to the materials and tasks (Heer \& Bostock, 2010; Kittur, Chi, \& Suh, 2008) with an emphasis on the video and uninterrupted survey response. After they agreed to the consent, they were subsequently presented with the demographic inventory, BFI 10-Item and DASS-21 Item. Next, participants were randomly assigned to one of the two groups: awe (experimental) condition or the amusement (control) condition (Shiota et al. 2007), whereas they were asked to watch the clip that matched their condition. Before showing the clip, we reiterated that attention should be paid to the video which is required to be watched uninterrupted, in full screen and with sound output available, and how otherwise they might not be able to answer the attention checks and as a result will get screened out. The awe video was shown to the experimental group and the amusement video to the control (Valdesolo, 2014). Immediately after watching the video, we presented four instructional manipulation check (IMC) questions (Oppenheimer \& Davidenko, 2009), which if they failed, they were screened out and 
instructed to get partial compensation. To the ones who remained in the experiment, we presented the emotion manipulation check questions (EMC's). Next, both groups were asked to fill out the hopelessness (HPSS/HPST) scales. Lastly, for exploratory purposes, we administered both subscales of the RRS (brooding and reflective rumination). A sitemap of the online experiment and the required action to progress between phases, is presented in the Figure 2.
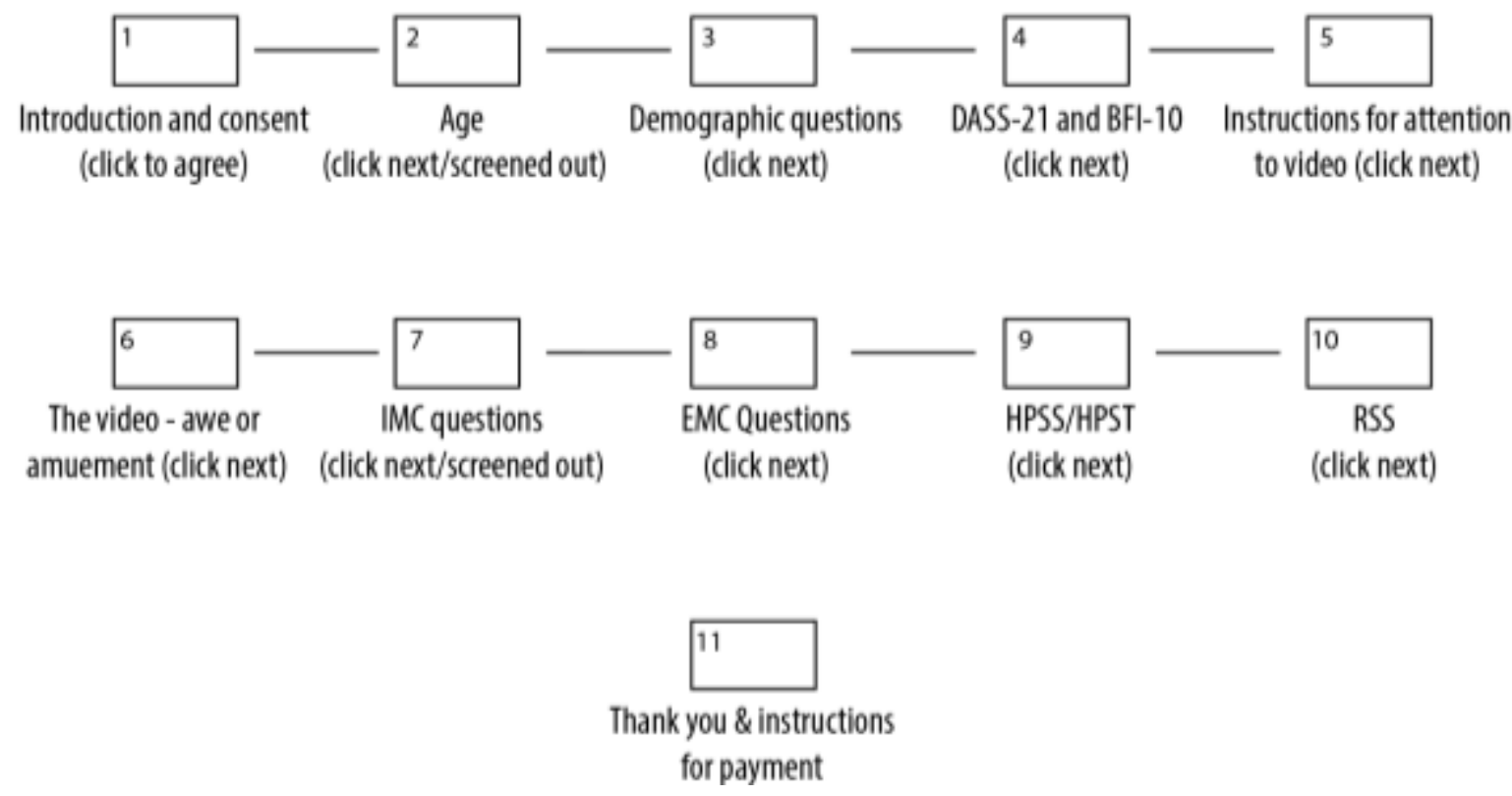

Figure 1. Sitemap of the experiment as viewed by the participants in Qualtrics.

We also included a progress bar so that respondents had an idea how far they had progressed with each page of the survey they saw. The online experiment concluded with a thank you note and instructions on how to claim the compensation on MTurk.

\section{Design}

Our study employed a quasi-experimental design, with participants randomly assigned to the video (awe or amusement) conditions. To assure that this random assignment led to equality among both groups with respect to various demographic 
variables, we conducted a series of t-tests. To test our main hypotheses regarding the effects of awe on hopelessness, we conducted a t-test and a series of correlations and hierarchical multiple regressions. For example, we performed correlation analysis that looked at the association of awe versus the control group with hopelessness score. Then, we measured awe's predictive strength of lower hopelessness score, over and above demographics and neuroticism. And finally, we performed post-hoc analyses which included another MRC where we treated levels of awe as moderator of the predictive strength of what condition participants were in.

\section{Results}

\section{Data Cleaning}

Prior to the analyses, each submitted survey was analyzed for completeness and correctness of the attention check answers. Individuals who repeatedly chose the same statement/response for different questionnaires as well as failed an instructional manipulation check (e.g. "For this question, just answer disagree") while displaying a shorter study completion time were excluded from the analysis under the assumption that their responses did not demonstrate a mindful participation in the study. Similarly, participants who did not pass more than three of the four video attention check questions were screened out. We took similar measures with respondents who used IP proxies located on territories that were not English speaking. From a total of 293 responses that we collected, 271 responses were included in our analyses $(N=$ 271).

\section{Descriptive Statistics}

Descriptive statistics were computed to understand the distribution of the variables within the sample and are reported in Table 1 . Gender was fairly equally 
distributed, $55 \%$ of the subjects being male and $45 \%$ female out of the subjects who were randomly selected to be in the awe condition (AWC) and $45.7 \%$ female, $54.3 \%$ male for those in the amusement condition (AMC). Participants' ages ranged from 18 to 69 years with an average age of $35.9(S D=11.4)$ for the participants in the AWC. The average age of the subjects in AMC was 36.2 years old $(S D=11.7)$. Overall, age was not normally distributed with a skewness of .93 $(S E=.15)$ and kurtosis of 3.93 $(S E=0.10)$. Therefore, we report the median age as a more reliable measure of central tendency for skewed distributions, which for our sample is 33 years old.

As far as the ethnicity of the respondents, the sample was heavily Caucasian (80\%). The breakdown of African-American ethnicity was $7.4 \%$ in the awe group and $7.2 \%$ in the amusement group, while there were $11.8 \%$ Asian-Americans in the awe group versus $6.5 \%$ in that of the amusement group. In contrast, educational attainment level seems to be normally distributed in the sample. From the total of the subjects in the AWC, 35.3\% reported to have had completed at least a bachelor degree in college as opposed to the AMC group which reported this statistic to be $32.6 \%$. Roughly $15 \%$ in both conditions were unemployed, either seeking work, studying at the time or not interested to work while the rest was working for wages $(59.6 \%)$. The variable that measures how much time the participants spend in nature is also normally distributed with a mean value of $3.04(S D=1.78)$ ranging from a score of $0-8$, indicative that our sample spends only a moderate amount of time in nature.

Personality variables were also measured, with the two main traits of interest being neuroticism and openness to experience. Neuroticism was normally distributed in both film condition groups $(M=5.4, S D=2.4)$. However, openness to experience had a higher mean score than neuroticism $(M=7.5, S D=2.0)$. 
Table 1

Descriptive Statistics

\begin{tabular}{|c|c|c|c|c|}
\hline \multirow[b]{2}{*}{ Variable } & \multicolumn{2}{|c|}{ Awe Condition } & \multicolumn{2}{|c|}{ Amusement Condition } \\
\hline & $n$ & $\begin{array}{l}M / P c t \\
(S D)\end{array}$ & $n$ & $\begin{array}{l}M / P c t \\
(S D)\end{array}$ \\
\hline Age & 135 & $\begin{array}{l}34.7 \\
(10.81)\end{array}$ & 138 & $\begin{array}{c}36.2 \\
(11.74)\end{array}$ \\
\hline \multicolumn{5}{|l|}{ Gender } \\
\hline Female & 60 & $44.1 \%$ & 63 & $45.7 \%$ \\
\hline Male & 76 & $55.9 \%$ & 75 & $54.3 \%$ \\
\hline \multicolumn{5}{|l|}{ Education } \\
\hline Less than high school degree & 2 & $1.50 \%$ & 0 & 0 \\
\hline High school graduate & 20 & $14.70 \%$ & 19 & $13.8 \%$ \\
\hline Some college but no degree & 33 & $24.30 \%$ & 40 & $29 \%$ \\
\hline Associate degree in college (2-year) & 18 & $13.20 \%$ & 20 & $14.5 \%$ \\
\hline Bachelor's degree in college (4-year) & 51 & $37.50 \%$ & 45 & $32.6 \%$ \\
\hline Master's degree & 10 & $7.40 \%$ & 6 & $4.3 \%$ \\
\hline Doctoral degree & 1 & $0.70 \%$ & 5 & $3.6 \%$ \\
\hline $\begin{array}{l}\text { Professional degree (JD, MD) } \\
\text { Ethnicity }\end{array}$ & 1 & $0.70 \%$ & 3 & $2.2 \%$ \\
\hline Native American / Alaska Native & 2 & $1.50 \%$ & 0 & 0 \\
\hline Asian American & 16 & $11.80 \%$ & 9 & $6.50 \%$ \\
\hline African American & 10 & $7.40 \%$ & 10 & $7.20 \%$ \\
\hline Native Hawaiian / Pacific Islander & 0 & 0 & 1 & $0.70 \%$ \\
\hline Caucasian & 106 & $77.90 \%$ & 112 & $81.20 \%$ \\
\hline Other & 2 & $1.50 \%$ & 6 & $4.30 \%$ \\
\hline \multicolumn{5}{|l|}{ Employment Status } \\
\hline Working for wages & 81 & $59.60 \%$ & 83 & $60.10 \%$ \\
\hline Self-employed & 23 & $16.90 \%$ & 19 & $13.80 \%$ \\
\hline Out of work and looking for work & 12 & $8.80 \%$ & 11 & $8.00 \%$ \\
\hline Out of work but not currently looking for & 5 & $3.70 \%$ & 3 & $2.20 \%$ \\
\hline Stay at home parent & 4 & $2.90 \%$ & 6 & $4.30 \%$ \\
\hline Student & 5 & $3.70 \%$ & 9 & $6.50 \%$ \\
\hline Retired & 3 & $2.20 \%$ & 5 & $3.60 \%$ \\
\hline Not able to work & 3 & $2.20 \%$ & 2 & $1.40 \%$ \\
\hline Time Spent in Nature & 136 & $\begin{array}{l}2.87 \\
(1.69)\end{array}$ & 138 & $\begin{array}{l}3.21 \\
(1.86)\end{array}$ \\
\hline Neuroticism & 135 & $\begin{array}{l}5.41 \\
(2.40)\end{array}$ & 138 & $\begin{array}{l}5.4 \\
(2.51)\end{array}$ \\
\hline Openness to Experience & 136 & $\begin{array}{l}7.50 \\
(2.01)\end{array}$ & 138 & $\begin{array}{l}7.5 \\
(1.94)\end{array}$ \\
\hline
\end{tabular}

Note. $N=274$ for the combined groups.

Depression scores (DASS-D) were not normally distributed, with a moderate positive skewness of $.90(S E=-.46)$, which can be explained by the fact that our 
sample is not comprised of clinically depressed subjects. AWC subjects reported an average score of $4.5(S D=4.6)$ and AMC reported $3.8(S D=4.3)$. Purely descriptively, it can be seen that the AMC participants have a slightly lower depression score than the AWC participants. To increase the usability of the variable in later mean comparison statistics, we normalized the distribution using log transformation. After log transformations, the DASS-D score seemed more normally distributed in the entire sample $(M=.62, S D=.39)$.

\section{Sample Equivalency}

We established normalcy of the sample by satisfying two criteria: a) assigning the participants randomly to a video condition and b) by confirming that there were no significant mean differences in variables of interest between conditions. Whether the second criterion was met was determined by performing a series of t-tests between the two video conditions (awe and amusement) on the following variables: 21 -item DASS, neuroticism, openness to experience, age, and level of education as independent variables., the results of which we have presented in Table 2. The two conditions did not differ significantly on any of these listed variables, indicating that randomization created equivalent groups. 
Table 2

Group Differences by Condition

\begin{tabular}{lcccc}
\hline & Awe & Amusement & t-score & Effect Size \\
\hline Psychological and Ideological & $M(S D)$ & $M(S D)$ & $t$ & Cohen's $d$ \\
\hline DASS 21-items & & & &. \\
$\quad$ Depression Subscale & $4.45(4.60)$ & $3.80(4.30)$ & 1.23 & .14 \\
$\quad$ Anxiety Subscale & $3.50(4.40)$ & $3.40(4.35)$ & .25 & .03 \\
$\quad$ Stress Subscale & $6.40(5.50)$ & $6.10(5.90)$ & .50 & .06 \\
Age & $34.81(10.8)$ & $36.2(11.8)$ & -1.02 & .01 \\
Education & $4.00(1.36)$ & $4.04(1.42)$ & -.30 & .03 \\
Neuroticism & $5.40(2.40)$ & $5.36(2.51)$ & .14 & .01 \\
Openness to Experience & $7.50(2.00)$ & $7.50(1.95)$ & .06 & .00 \\
\hline
\end{tabular}

Note. $N=272 .{ }^{*} p<.05 ; * * p<.001$; DASS denote Depression, Anxiety and Stress Scale.

\section{Manipulation Check}

We reported mean levels of awe experience for each group after watching the video that corresponded to their group. For example, all participants were asked "How much awe did you experience while watching this video?" and "How much amusement did you experience while watching this video?" Further, both groups were asked the extent to which the images were awe-inspiring to them, the extent to which they made participants feel like a part of something greater, and how much the participants felt that there was something greater out there. View Table 3 for an overview of the extent to which the manipulation had an effect. The awe video clearly inspired more awe than the amusement video. The mean score for the question that measured how much awe participant's experienced after watching the video were higher in the awe group $(M=5.09, S D=1.68)$ than the amusement group $(M=2.71$, $S D=2.04)$, showing that the manipulation had an effect. Similarly, people in the amusement condition were more amused $(M=5.07, S D=1.77)$ than those in the awe condition $(M=3.84, S D=2.07)$. Furthermore, we assessed how awe-inspiring 
participants found the sensory information - images on each video condition. Note that this question did not measure the level of awe experienced but it rated the quality of the sensory information of each video, as elicitors of awe. As expected, participants found the images highly awe-inspiring in the awe condition $(M=5.21, S D=1.63)$, but less awe inspiring in the amusement video condition $(M=2.91, S D=2.14)$. The awe video also caused the participants to feel very much that they were a part of a grander scheme $(M=5.24, S D=1.93)$. Finally, $81.6 \%$ of the participants in the awe condition said that they felt awestruck, whereas $16.9 \%$ said that they didn't, suggesting that the majority felt awe-stuck. By contrast, $30.1 \%$ of those in the amusement condition answered yes to the same question and $69.1 \%$ of the sample answered no.

Table 3

Manipulation Check Results

\begin{tabular}{|c|c|c|}
\hline & Awe Condition & Amusement Condition \\
\hline Manipulation Check Variables ${ }^{a}$ & $M(S D) / P c t$ & $M(S D) / P c t$ \\
\hline Experienced Awe & $5.0(1.7)$ & $2.7(2.04)$ \\
\hline Experienced Amusement & $3.8(2.0)$ & $5(1.8)$ \\
\hline Images were awe-inspiring & $5.2(1.63)$ & $2.9(2.1)$ \\
\hline There is something greater & $3.1(2.07)$ & $2(1.9)$ \\
\hline Feel like a part of something greater & $5.2(1.92)$ & $2.6(2.18)$ \\
\hline \multicolumn{3}{|l|}{ Were you Awe-struck ${ }^{b}$} \\
\hline Yes & $81.6 \%$ & $30.1 \%$ \\
\hline No & $16.9 \%$ & $69.1 \%$ \\
\hline
\end{tabular}

\section{Hypothesis Testing}

To test our main hypothesis that participants in the awe video condition will have lower state hopelessness score than those in the amusement video condition (H1-a), we analyzed the mean differences in hopelessness score between the two conditions 
(see Table 2). Conducting an independent samples $t$-test, we found that state hopelessness in the awe condition $(M=23.1, S D=5.24)$ did not significantly differ from that of the amusement condition $(M=22.7, S D=3.53), t(268)=.52, p>.05$. Similarly, there was no significant difference in the trait hopelessness score between the awe group $(M=29.1, S D=6.13)$ and amusement $(M=27.9, S D=5.90), t(268)=$ $1.62, p>.05$. These findings do not support our research hypothesis $(\mathrm{H} 1)$ that participants will display lower hopelessness scores by just being in the awe condition versus that of amusement.

Using the same logic and analysis, we explored whether the video manipulation produced a different outcome for the brooding or reflection factor of the Ruminative Response Scale (RRS) as a dependent variable (H3). Participants in the awe condition reported significantly lower brooding rumination $(M=9.13, S D=3.50)$ than those in the amusement condition $(M=10, S D=4)$. A one-tailed independent sample t-test showed that there is indeed a statistically significant group difference in the brooding rumination between the awe and control conditions, $t(267)=1.83, p<.05$. No significant differences, however, were found between awe and amusement for the reflection dimension of the RRS, $t(267)=-.47, n s$. We presented the results of the $\mathrm{t}-$ tests between conditions for all the outcome variables in Table 4. The current findings support our hypothesis that being in the awe condition does predict lower brooding rumination score to our expectation, but with a modest effect size, $(d=-.22)$. However, as expected, awe did not predict any significant changes in the reflective rumination score. 
Table 4

Comparing Awe and Amusement on Hopelessness and Rumination

\begin{tabular}{ccccc}
\hline & Awe & Amusement & t-score & Effect Size \\
\hline Outcome Variables & $M(S D)$ & $M(S D)$ & $t$ & Cohen's $d$ \\
\hline S/THS & & & & \\
State Hopelessness & $23.10(5.34)$ & $22.70(5.35)$ & ${ }^{\mathrm{a}} .52$ & .06 \\
$\quad$ Trait Hopelessness & $29.10(6.13)$ & $27.90(5.90)$ & ${ }^{\mathrm{a}} .25$ & .03 \\
RRS & & & & \\
$\quad$ Brooding Rumination & $9.13(3.50)$ & $10.00(4.00)$ & ${ }^{\mathrm{b}}-1.83^{*}$ & -.22 \\
$\quad$ Reflective Rumination & $9.40(3.80)$ & $9.62(3.80)$ & ${ }^{\mathrm{b}}-.47$ & -.05 \\
\hline
\end{tabular}

Note. $N=270 .{ }^{*} p<.05 ;{ }^{* *} p<.001 ;{ }^{a}$ two-tailed t-test; ${ }^{\mathrm{b}}$ one-tailed t-test; S/THS denotes State/Trait Hopelessness Scale, RSS denotes Ruminative Response Scale

Additionally, we computed one-tailed Pearson correlations to understand the strength of the relationship between the condition (dummy coded: awe $=0$, amusement $=1$ ), and both our outcome variables, state hopelessness and rumination in terms of a correlation, as a secondary aspect of our main hypothesis (H1-b). A matrix depicting the correlations between the conditions and all outcome variables is presented in Table 5. We did not observe a significant association between state hopelessness and the video condition $(r=.03, n s)$. When we performed the same analysis with rumination as an outcome variable, we found that only brooding rumination was negatively significantly related to the type of condition participants was in $(r=-.11, p<.05)$ indicating that lower brooding scores were mildly associated with the awe condition. These findings were consistent with those from the previous analysis. 
Table 5

Pearson (r) Hopelessness-Condition and Rumination-Condition correlations (subscales)

\begin{tabular}{|c|c|c|c|c|c|}
\hline Variables & 1 & 2 & 3 & 4 & 5 \\
\hline 1. ${ }^{\mathrm{a}}$ Condition & -- & & & & \\
\hline 2. ${ }^{\mathrm{b}}$ State Hopelessness & .32 & -- & & & \\
\hline 3. ${ }^{\mathrm{b}}$ Trait Hopelessness & 0.10 & $0.85 * *$ & -- & & \\
\hline 4. ${ }^{\mathrm{c}}$ Reflective Rumination & -0.03 & $0.14^{*}$ & $0.24 * *$ & -- & \\
\hline 5. ${ }^{\mathrm{c}}$ Brooding Rumination & $-0.11^{*}$ & $0.50 * *$ & $0.61 * *$ & $0.53 * *$ & -- \\
\hline
\end{tabular}

\section{Hierarchical Multiple Regression Analysis}

To test our second hypothesis, that level of awe predicts lower scores of hopelessness above and beyond demographics and neuroticism, we performed a twostep hierarchical multiple regression analysis with state hopelessness as the outcome variable. Demographic variables (age, gender, neuroticism) were entered in the first step because we wanted to control for these variables. In the second step, we added the level of experienced awe and the video condition (dummy coded as awe $=1$, amusement $=0$ ). We entered the variables in this order because we hypothesized that the extent to which the individual experienced awe after watching the video and being in one or the other condition would predict lower hopelessness scores above and beyond demographics and the personality variable of neuroticism. It should be noted that the independent variables were not correlated with each other, fulfilling one of the main MRC analysis assumptions which is to avoid multicollinearity, as shown in Table 6. 
Table 6

Pearson (r) Correlations Between MRC Variables

\begin{tabular}{|c|c|c|c|c|c|c|c|}
\hline & Variable & 1 & 2 & 3 & 4 & 5 & 6 \\
\hline 1. & State Hopelessness & -- & & & & & \\
\hline 2. & Age & -.09 & -- & & & & \\
\hline 3. & Gender & -.05 & $.12 *$ & -- & & & \\
\hline 4. & Neuroticism & $.51 * * *$ & $-.18 * * *$ & .08 & -- & & \\
\hline 5 . & Level of awe experience & $-.14 * *$ & $.10^{*}$ & $.10^{*}$ & -.03 & -- & \\
\hline 6. & Condition & .03 & -.07 & -.01 & -.01 & $.50 * * *$ & -- \\
\hline
\end{tabular}

Notes. $N=268$. Condition was dummy coded: Awe $=1$, Amusement $=0$; Significance level at $* p<.05, * * p<.01, * * * p<.001$.

The first step of the hierarchical multiple regression analysis (see Table 7) revealed that demographic factors (age, gender, neuroticism) contributed significantly to the regression model with $R^{2}=.27, R^{2}$ adj $=.26$, and $F(3,264)=32.85, p<.001$, accounting for $27 \%$ of the total variance in predicting state hopelessness. However, when each variable was tested for their unique contribution, we found that only neuroticism with $\beta=.52, t=9.75, p<.001$ could uniquely predict the criterion, indicating that the more neurotic the individual, the higher hopelessness they experienced after watching the video. Whether the participants were male or female, or younger or older did not predict hopelessness.

In the second step, we added the condition (awe video or amusement video) and the level of awe experienced to the model and found that the two steps together explain $30 \%$ of variance in the state hopelessness score with $R^{2}=.30, R^{2}$ adj $=.29$ confirmed by a test of significance that yielded $F(5,262)=22.41, p<.001$. For the variables added in the second step, there was a marginal but significant increase with an increment of $3 \%\left(F(5,262)=22.41, p<.001, R_{\text {change }}^{2}=.03\right)$ in variance in state hopelessness as it can be seen in Table 7. In terms of evaluating the second step 
predictors, whether participants watched the awe video or amusement video did make a statistically significant unique contribution to the to the model with $\beta=.13, t=2.19$, $p<.05$. The level of awe that participants experienced also made a significant unique contribution to the model $(\beta=-.19, \mathrm{t}=-3.15, \mathrm{p}<.01)$, indicating that when participants got awe-inspired by the images in the video, it predicted lower scores in state hopelessness.

\section{Table 7}

Hierarchical MRC: Demographics, Personality, Level of Awe, and Condition as Predictors of State Hopelessness

\begin{tabular}{ccccc} 
Predictors & $\beta$ & $s r^{2} \mathrm{a}$ & $R^{2}$ & $\Delta R^{2}$ \\
\hline Step 1: Demographic & & & $.52^{* * *}$ & .00 \\
Age & .02 & .01 & & \\
Gender & -.09 & -.09 & & \\
Neuroticism & $.51^{* * *}$ & .51 & & $.05^{* * *}$ \\
\hline Step 2: Level of Awe \& Condition & & & & \\
Level of awe & $-.19^{* *}$ & -.16 & & \\
Condition & .13 & .11 & & \\
\hline
\end{tabular}

Note. ${ }^{*} p<.05, * * p<.01, * * * p<.001 ;{ }^{\mathrm{a}} s r^{2}$ represents unique variance explained; $N$ = 268. Gender coded: 1 = male, 2 = female; Condition coded: $1=$ awe, $0=$ amusement.

Conclusively, MRC analyses show that when the level of awe is added to the model, namely when the model considers how much awe, if any, have the participants experienced, the amount of the variance explained increases. The inclusion of this variable also makes the condition a significant contributor. Thus, it makes sense to rely on results that incorporate a successful manipulation check, rather than just consider the condition blindly without the information whether it is making an impact. Driven by these findings, we performed additional analysis emphasizing the level of awe as a moderator of the results. 


\section{Post-hoc Analyses}

With a rich database of responses, it seemed feasible to perform post-hoc analyses that enrich the explanations behind our predicted results. Some of these analyses were conducted in response to unplanned findings that emerged from hypothesis testing but are altogether reported in Table 8.

Analyzing Level of Awe as a Moderator. The results of the hierarchical MRC revealed that higher levels of awe experienced do predict lower scores of state hopelessness above and beyond demographics and neuroticism. Considering that we obtained non-significant results when testing the first hypothesis which did not include level of awe as predictor, namely an analysis that did not acknowledge the manipulation check and instead employed a dichotomous predictive style, we decided to treat level of awe experienced as a moderator in our next analysis. In this case, we consider hopelessness score to be a function of the level of awe as derived by the impact of the condition (e.g. participants in awe condition would have experienced higher level of awe). We referred to this as an interaction between these two variables and we labeled it Level x Condition. We already know that participants in the awe condition did indeed experience high levels of awe $(M=5.09, S D=1.68)$ after watching the video, so it is safe to assume that the manipulation did have an effect and therefore the variable as such can be predictive of the impact of condition on hopelessness score. To test this interaction, we conducted a hierarchical MRC that included Condition and Level of Awe as independent variables in the first step of the model. Then we added the interaction Level x Condition in the second step. Both models yielded significant results. In the first step, Level of Awe and Condition explained $4 \%$ of the variance in State Hopelessness Scores with $R=.04, \mathrm{R}^{2}$ adj $=.03$ 
confirmed by a test of significance that yielded $F(2,267)=4.82, p<.01$. Level of Awe made a significant unique contribution to the model $(\beta=-.21, t=-3.06, \mathrm{p}<.01)$, and so did Condition $(\beta=.14, t=2.00, \mathrm{p}<.05)$.

In the second step, when we added the Level X Condition interaction, we found that together the two direct effects and the interaction effect explained $9 \%$ of the variance $\left(R=.09, \mathrm{R}^{2}\right.$ adj $\left.=.08, F(1,266), p<.001\right)$. More importantly, we found that the interaction variable Levels $\mathrm{x}$ Condition added a significant amount of explained variance in hopelessness, by introducing an increment of $6 \%$ in the additional variance explained with a reported $R_{\text {change }}^{2}=.06, F(1,266)=16.43, p<.01$. This means that the interaction between the levels of awe that participant experienced and which condition they participants were in, namely which video they saw, determines what is the impact of the Levels of Awe and Condition as IV's.

Table 8

Hierarchical MRC: Level of Awe, Condition and Level x Condition Interaction as Predictors of State Hopelessness

\begin{tabular}{ccccc}
\hline \multicolumn{1}{c}{ Predictors } & $B$ & $s r^{2 \mathrm{a}}$ & $R^{2}$ & $\Delta R^{2}$ \\
\hline Step 1: & & & $.04 * *$ & .04 \\
Level of Awe & $-.21^{* *}$ & -.19 & & \\
Condition & $.14^{*}$ & .12 & & $.06 * * *$ \\
\hline Step 2: Interaction & & & .06 \\
$\quad$ Level x Condition & $.80 * * *$ & .24 & &
\end{tabular}

Note. ${ }^{*} p<.05,{ }^{*} p<.01,{ }^{* * *} p<.001 ;{ }^{\mathrm{a}} s r^{2}$ represents unique variance explained; $N=268$. Gender coded: $1=$ male, $2=$ female; Condition coded: $1=$ awe, $0=$ amusement.

Other Post-hoc and Unplanned Analyses. Another set of analyses was conducted in response to the results obtained when testing hypothesis 2 . We found that the level of awe does only marginally increase the amount of variance explained. Besides other factors, we can attribute the small change in variance explained to the 
fact that the awe video might have not challenged some individuals frame of reference the same as others. In other words, while the images elicited awe in a number of respondents, it failed to do so for others. To test this assumption, we looked at the association between a dichotomous variable we included in the study that simply asked participants whether they felt awestruck after watching the video (yes coded 1, no coded 0) with the assessment of how much awe-inspiring the images in the awe video seemed to them. Our aim was to discover if the perception that images of the video were indeed awe-inspiring is any indication whether participants felt awestruck. This analysis is meant to help eliminate any other outside factors as responsible for the participants feeling awestruck. We found a moderately strong correlation between the two with $\mathrm{r}_{\mathrm{pb}}=.64, \mathrm{p}<.001$, indicating a great likelihood that participants in the awe condition felt awe because they found the images awe-inspiring, and not for any other reason (e.g. external factors, remembered an instance when they felt awe before or just randomly chose a value).

Lastly, we were interested to find out if being in the awe video condition would predict hopelessness within a selected sample of respondents whose score met the criteria for the presence of depressive symptoms (DASS-D score greater than 9). However, we found non-significant results which were inconclusive given that our analysis was significantly statistically underpowered due to the small number of participants meeting the criteria to be included in the analysis. $(N=29$ for the awe group, $N=23$ for the amusement group).

\section{Discussion}

Following a series of rich analyses, the current study offers evidence that an increased state experience of awe is related to a decrease in hopelessness when we 
take into account the extent to which individuals experienced awe. Our results show that when individuals felt awe after watching the video, they reported lower scores of hopelessness. This finding remained even after we held constant individual's neurotic tendencies by controlling for neuroticism, a well-known predictor of negative affect (Bagby \& Parker, 2001).

Furthermore, we predicted that being in the awe condition, namely watching the awe clip versus the amusement clip alone, would predicte lower levels of hopelessness. This hypothesis, however, was not supported. Not taking into account how much the individuals experienced awe, we found that whether they saw an aweinspiring video or just an amusing clip did not predict hopelessness. Given the online format of the experiment and the decreased visible control we had upon administering the manipulation, we cannot conclude that all participants experienced awe just by being in the awe video condition. Therefore, we suggest that including the level of awe to the analysis is important in future studies.

\section{Predicting Brooding Rumination}

We also explored the relationship between awe and brooding rumination. As predicted, we found that individuals that watched the awe video reported lower brooding rumination scores. We expected such results, knowing that brooding rumination represents an unhealthy, namely counterproductive, adverse mental condition (Whitmer, \& Gotlib, 2013) that keeps one in a passive state of recounting negative events surrounding his or her life. On a neurobiological level, rumination is thought to be represented by a heightened emotional reactivity preceded with the activation of brain structures that a growing body of research finds responsible for negative affect, such as the subgenual prefrontal cortex (sgPFC) (Bratman, Hamilton, 
Hahn, Daily \& Gross, 2015). A direct measurement of changes in activity of sgPFC, should be considered for future studies involving the effects of awe. However, it should be noted that although the correlation between the level of awe experienced and the decrease in self-reported brooding rumination was small, such correlation was significant and the nature of the change was conform our prediction. It is possible that if we had a clinical sample, we could have observed a greater negative correlation value between these two variables.

On the other hand, we did not find evidence to suggest that awe as a video condition has a negative relationship with reflective rumination, as measured by the reflection subscale of RRS. We theorize that such results are due to the nature of this subscale which is constructed to assesses a more constructive form of ruminating. This type of rumination is characteristic for individuals who are repeatedly focused on the negative aspects of life and self that can be changed, making this type of ruminations less maladaptive than the brooding rumination (Treynor \& NolenHoeksema, 2013) as well as harder to detect and predict.

\section{Awe and Nature}

Knowing that nature is a strong elicitor of awe, we wondered, does how much time we spend in nature determine how hopeless we feel? In a series of post-hoc analyses, we looked at the contribution of time spent in nature as predictor of hopelessness. A version of a MRC model that included time spent in nature together with the demographics in a first step and condition and level of awe in a second step reported that the first step explained $32 \%$ of variance in state hopelessness, while the second step explained an additional $5 \%$ of variance. This result confirms first the idea that spending time in nature is associated with lower levels of hopelessness, and 
second that experiencing awe still explains variance in hopelessness over and above time spent in nature.

This finding supports previous research that has linked spending time in nature with a decrease in negative affect and similarly, city living with a negative impact on mental health (Dadvand et al., 2015; Lederbogen et al., 2011). More specifically, researchers have found evidence that spending time in nature helps to lower rumination, characteristic in depressive states, and does so by suppressing the activity in sgPFC (Bratman et al. 2015). Studies show that SgPFC activity increases when the person is experiencing sadness or negative self-reflecting processes associated with depression (Kross, Davidson, Weber \& Ochsner, 2009). It is interesting to note that nature and level of awe experienced for the awe video condition were not significantly correlated with each other, suggesting that the amount of time the person spends in nature does not necessarily indicate how likely that person is to experience awe when watching the awe video.

\section{Level of Awe as a Moderator}

We found that there was an increase in explained variance in hopelessness if we considered the interaction between the level of awe and video condition, a finding that suggests that how much awe one experiences moderates the relationship between watching a video on awe and hopelessness. Through MRC analysis, we had already established that the combined level of awe and watching the awe video (versus the amusement) predicted lower scores of state hopelessness. Adding the interaction to the analysis, we found that the higher the level of awe experienced and the higher the film condition category $($ awe $=1$, amusement $=0$ ), the lower the hopelessness score. Seeing the awe inducing video alone is not enough to lower hopelessness, but when 
combined with how much awe one experiences from watching the film, levels of hopelessness are decreased.

\section{Limitations}

Although a considerable effort was placed on controlling most aspects of the study with the aim of producing valid and generalizable answers, like all research this study had limitations. One of the limitations relates to the fact that with the current online format, the hypothesis about awe and hopelessness could not be tested on a clinically depressed sample. It is possible that if we had a clinically depressed sample, the amount of change could be more visible and the predictive abilities of the variables could show greater strength. The lack of a depressive tendency in the sample, as established by the low score of DASS-D, indicates a lack of the presence of depressive symptoms. This could be the reason why we did not obtain significance when testing for awe mean differences in hopelessness. Even when we tried to compute post hoc' analysis with a group that met the criteria for the presence of depressive symptoms, we found the group so small and the analysis underpowered.

Another observation we made is that our sample seems highly open to experience. Openness has been found to be associated with higher experiencing of awe for space images (Silvia, et al. 2015) but does not predict negative affect (Kotov, Gamez, Schmidt \& Watson, 2010). It is possible that with a dominating personality dimension such as openness, our sample was inclined to not experience much hopelessness to begin with.

Moreover, although we made every effort to exclude people who were not paying attention to the video, because this was an online study, we do not fully know how distracted participants were when actually watching the video. If they were distracted 
with other tasks, this would lower the impact of the film and this might explain the small effect that film alone had on hopelessness.

Finally, the biggest limitation of all was the inability to perform a full experimental manipulation where the participants could be monitored to ensure proper attention was paid to the video and awe was indeed induced and would match the self-reported scores of the emotion manipulation check. Additionally, an in-person experiment would allow for a pre and post design that would increase our confidence that changes in dysphoric mood are entirely attributed to our manipulation. While conducting a pre and post experimental manipulation with an online sample is technically possible also, there are a few actions associated with that type of design that are difficult to perform in the online format and could ultimately end hindering the validity of the results. For example, we would have not been able to monitor the participants (e.g. in person or video) during the manipulation which requires a time effect (usually achieved by introducing a filler task). Such a time effect in a pre and post design would help ensure that the experiment feels natural between administering the same measure twice, as well as would help allow for some time to pass for without the individual leaving the experiment.

\section{Implications and Future Directions}

By exploring the relationship between these variables, we found results to support the idea that awe could be responsible for a decrease in a dysphoric mood. Reported levels of hopelessness decreased after watching a film that induced awe at least in those participants who experienced high levels of awe during the film. By choosing amusement as a control condition, we can be at more liberty to theoretically attribute the effects of this positive change to qualities of awe as a unique positive emotion 
rather than the positive emotional valence associated with it. However, this theorizing was not fully experimentally proven, so for now it should remain a concept in need of further experimental testing. Our findings also showed us that age did not play a significant role in predicting hopelessness either before or after one has been aweinspired. Similarly, we found that men and women responded the same way to the film condition and their experience of awe.

Ultimately, it is somewhat difficult to confidently pinpoint which aspects of awe are mostly responsible for its predictive ability on hopelessness. We can somewhat rely on our post-hoc analysis which denoted a high positive correlation between the level of awe experienced and the extent to which the participants found the images in the awe video condition to challenge their current frame of reference. This means the more participants felt awe inspired after watching the awe clip, the more they found the images challenging to their current frame of knowledge. Since levels of awe did predict low hopelessness, we can infer that challenging the current frame of knowledge did take place and could also be related to lower hopelessness scores, as a product of experiencing awe (e.g. need for accommodation). If we go back to the very definition of awe and its elicitors, we see that the need for accommodation was one of the main conditions necessary to take place for the individual to experience awe. In this case, we can argue that this need for accommodation is probably occurring as individuals indicate that they have experienced awe. So, it seems that to understand and give meaning to these results, we should consider the elicitors and effects of awe as theories discussed here have suggested.

Now that we know that awe is somewhat negatively associated with negative affect, we should focus on possible ways to apply this finding, both to benefit science 
and future research, but also in a practical and therapeutic way. That is, clinicians could consider nature and awe in treating people with depression and hopelessness. Another recommendation for future studies would be to test these concepts within a sample of clinically depressed patients. Significant findings that derive from a sample with depression would allow for more valid inferences and might produce concrete evidence for endorsing awe in therapeutic programs. And lastly, future research should explore the longevity of the effects of awe. For example, Fredrickson (1998; $2000 ; 2001)$ found that the effects of positive emotions accumulate with time and compound such that they create psychological resiliency. To date, there is no evidence that indicates how sustainable the affective state is or what underlying mechanisms prolong or maintain the positive effects resulting from that state. Is it the frequency of exposure? Perhaps the how well the awe-inspiring stimuli complements one's perceptual preferences or interests and goals? This should be researched further.

Something to consider is what direction to take methodologically when constructing future studies on the positive effects of awe. The online format of the experiment seemed to have served a good purpose for exploring the relationship of awe and hopelessness. However, it almost appears that such a format could at best offer exploratory results, but not a confirmatory outcome.

Additionally, to increase confidence that the findings cannot just be attributed to the positive valence of the emotional experience of awe, the same variables should be explored in a purely experimental design that could look at causation. This is best achieved in a non-virtual setting also. That would allow the experimenter to have full control of the manipulation and have the experiment feel more natural and spontaneous. 
Finally, because we found the awe condition did predict lower brooding rumination scores, we suggest that future researchers exploit these finding and design studies that explore the neural mechanisms behind this. For example, we recommend that researchers explore the effect of awe in inhibiting the neural activity of sgPFC which is found to be active during self-referential rumination episodes.

In the end, this study suggests that experiencing awe, often by scenes of nature, can have positive effects on our experience of hopelessness (and by extension, perhaps depression), but we need more experimental research to confirm these effects before we draw firm conclusions. This task is left for future researchers. 


\section{References}

Abramson, L. Y., Metalsky, G. I., \& Alloy, L. B. (1989). Hopeless depression: A theory based subtype of depression. Psychological Review, 96, 358-372.

Algoe, S. B., \& Haidt, J. (2009). Witnessing excellence in action: The 'other-praising' emotions of elevation, gratitude, and admiration. The Journal of Positive Psychology, 4, 105-127.

Antony, M. M., Bieling, P. J., Cox, B. J., Enns, M. W., \& Swinson, R. P. (1998). Psychometric properties of the 42-item and 21-item versions of the Depression Anxiety Stress Scales in clinical groups and a community sample.

Psychological Assessment, 10, 176-181.

Bagby, R. M., \& Parker, J. D. A. (2001). Relation of rumination and distraction with neuroticism and extraversion in a sample of patients with major depression. Cognitive Therapy and Research, 25, 91-102.

Beevers, C.G., Disner, S.G., Haigh, E.A.P., Beck, A.T., 2011. Neural mechanisms of the cognitive model of depression. Nature Reviews Neuroscience, 12, 467477.

Beck, A. T., Steer, R. A., \& Garbin, M. G. (1988). Psychometric properties of the Beck Depression Inventory: Twenty-five years of evaluation. Clinical Psychology Review, 8, 77-100.

Bratman, G. N., Hamilton, J. P., Hahn, K. S., Daily, G. C., \& Gross, J. J. (2015). Nature experience reduces rumination and subgenual prefrontal cortex activation. Proceedings of the National Academy of Sciences of the United States of America, 112, 8567-8572.

Brown, K. W., \& Ryan, R. M. (2003). The benefits of being present: mindfulness and its role in psychological well-being. Journal of Personality and Social Psychology, 84, 822-848.

Christie, A. M., Atkins, P. B., \& Donald, J. N. (2016). The meaning and doing of mindfulness: The role of values in the link between mindfulness and wellbeing. Mindfulness, 8, 368-378.

Cohen, S., Doyle, W. J., Turner, R. B., Alper, C. M., \& Skoner, D. P. (2003). Emotional Style and Susceptibility to the Common Cold. Psychosomatic Medicine, 65, 652-657.

Dadvand, P., Nieuwenhuijsen, M. J., Esnaola, M., Forns, J., Basagaña, X., AlvarezPedrerol, M., ... Sunyer, J. (2015). Green spaces and cognitive development in primary schoolchildren. Proceedings of the National Academy of Sciences of the United States of America, 112, 7937-7942. 
Demaree, H. A., Schmeichel, B. J., Robinson, J. L., \& Everhart, D. E. (2004).

Behavioural, affective, and physiological effects of negative and positive emotional exaggeration. Cognition and Emotion, 18, 1079-1097.

Fredrickson, B. L. (1998). What good are positive emotions? Review of General Psychology, 2, 300-319.

Fredrickson, B. L., \& Branigan, C. A. (2000). Positive emotions broaden action urges and the scope of attention. Manuscript in preparation.

Fredrickson, B. L. (2001). The role of positive emotions in positive psychology. The American Psychologist, 56, 218-226.

Goodman, J. K., Cryder, C. E., \& Cheema, A. (2013). Data collection in a flat world: The strengths and weaknesses of mechanical turk samples. Journal of Behavioral Decision Making. 26, 213-224

Green, S., Moll, J., Deakin, J.F.W., Hulleman, J., Zahn, R., (2013). Proneness to decreased negative emotions in major depressive disorder when blaming others rather than oneself. Psychopathology 46, 34-44.

Henrich, J., Heine, S. J., \& Norenzayan, A. (2010). The weirdest people in the world? The Behavioral and Brain Sciences, 33, 61-135.

Heer, J., \& Bostock, M. (2010, April). Crowdsourcing graphical perception: using mechanical turk to assess visualization design. In Proceedings of the SIGCHI Conference on Human Factors in Computing Systems (pp. 203-212). ACM.

Hayes, S.C., Follette, V.M., \& Linehan, M.M. (2004). Mindfulness and acceptance: Expanding the cognitive-behavioral tradition. New York: Guilford Press.

Just, N., \& Alloy, L. B. (1997). The response styles theory of depression: Tests and an extension of the theory. Journal of Abnormal Psychology, 106, 221-229.

Keltner, D., \& Haidt, J. (2003). Approaching awe a moral spiritual and aesthetic emotion. Cognition \& Emotion, 17, 297-314.

Kiecolt-Glaser, J. K., McGuire, L., Robles, T. F., \& Glaser, R. (2002). Emotions, morbidity, and mortality: New perspectives from psychoneuroimmunology. Annual Review of Psychology, 53, 83-107.

Kittur, A., Chi, E. H., \& Suh, B. (2008). Crowdsourcing user studies with Mechanical Turk. In M. Burnett, M. F. Costabile, T. Catarci, B. de Ruyter, D. Tan, M. Czerwinski, \& A. Lund (Eds.), Chi 2008: 26th Annual Chi Conference on Human Factors in SystemsComputing Systems Conference Proceedings.Vol. $1,453-456$. 
Kotov, R., Gamez, W., Schmidt, F., \& Watson, D. (2010). Linking 'big' personality traits to anxiety, depressive, and substance use disorders: A meta-analysis. Psychological Bulletin, 136, 768-821.

Kross E, Davidson M, Weber J, Ochsner K (2009) Coping with emotions past: The neural bases of regulating affect associated with negative autobiographical memo-ries. Biological Psychiatry, 65, 361-366.

Lederbogen, F., Kirsch, P., Haddad, L., Streit, F., Tost, H., Schuch, P., ... MeyerLindenberg, A. (2011). City living and urban upbringing affect neural social stress processing in humans. Nature, 474, 498-501.

Lovibond, P.F. \& Lovibond, S.H. (1995). The structure of negative emotional states: Comparison of the Depression Anxiety Stress Scales (DASS) with the Beck Depression and Anxiety Inventories. Behaviour Research and Therapy, 33, 335-334.

Maslow, A. H. (1964). Religions, values, and peak-experiences. Columbus: Ohio State University Press.

McCraty R, Atkinson M, Tiller WA, Rein G, Watkins AD (1995). The effects of emotions on short-term power spectrum analysis of heart rate variability. American Journal of Cardiology, 76, 1089-1093.

McDougall, W. (1910). An introduction to social psychology. Boston: J.W. Luce \& Co.

Metalsky, G. I., \& Joiner, T. E. (1992). Vulnerability to depressive symptomatology: A prospective test of the diathesis-stress and causal mediation components of the hopelessness theory of depression. Journal of Personality and Social Psychology, 63(4), 667-675.

Morrison, R., \& O'Connor, R. C. (2008). The role of rumination, attentional biases and stress in psychological distress. British Journal of Psychology, 99(Pt 2), 191-209.

Musser, E. D., Backs, R. W., Schmitt, C. F., Ablow, J. C., Measelle, J. R., \& Nigg, J. T.(2011). Emotion Regulation via the Autonomic Nervous System in Children with Attention-Deficit/Hyperactivity Disorder (ADHD). Journal of Abnormal Child Psychology, 39, 841-852.

Nolen-Hoeksema, S. (1991). Responses to depression and their effects on the duration of depressive episodes. Journal of Abnormal Psychology, 100, 569-582.

Nolen-Hoeksema, S., \& Morrow, J. (1991). A prospective study of depression and posttraumatic stress symptoms after a natural disaster: The 1989 Loma Prieta earthquake. Journal of Personality and Social Psychology, 61, 115-121. 
Nolen-Hoeksema, S., Wisco, B. E., \& Lyubomirsky, S. (2008). Rethinking Rumination. Perspectives on Psychological Science, 3(5), 400-424.

Isen, A. M. (2000). Positive affect and decision making. In M. Lewis \& J. M. Haviland (Eds.), Handbook of emotions (2nd ed., pp. 14 154). New York: Guilford Press.

Oppenheimer, D. M., Meyvis, T., \& Davidenko, N. (2009). Instructional manipulation checks: Detecting satisficing to increase statistical power. Journal of Experimental Social Psychology, 45, 867-872.

Piff, P. K., Dietze, P., Feinberg, M., Stancato, D. M., \& Keltner, D.. (2015). Awe, the small self, and prosocial behavior. Journal of Personality and Social Psychology, 108, 883-899.

Rammstedt, B., \& John, O. P. (2007). Measuring personality in one minute or less : A 10-item short version of the Big Five Inventory in English and German. Journal of Research in Personality, 41, 203-212.

Ryff, C. D., Singer, B. H., \& Dienberg Love, G. (2004). Positive health: Connecting well-being with biology. Philosophical Transactions of the Royal Society London B, 359, 1383-1394.

Schneider, S., \& Brassen, S. (2016). Brooding is related to neural alterations during autobiographical memory retrieval in aging. Frontiers in Aging Neuroscience, $8,1-11$.

Shiota, M. N., Keltner, D., \& Mossman, A. (2007). The nature of awe: Elicitors, appraisals, and effects on self-concept. Cognition \& Emotion, 21, 944-963.

Shiota, M. N., Neufeld, S. L., Yeung, W. H., Moser, S. E., \& Perea, E. F. (2011). Feeling good: Autonomic nervous system responding in five positive emotions. Emotion, 11, 1368-1378.

Silvia, P. J., Fayn, K., Nusbaum, E. C., \& Beaty, R. (2015). Openness to experience and awe in response to nature and music: Personality and profound aesthetic experiences. Psychology of Aesthetics, Creativity, and the Arts, 9, 376-384.

Stellar, J. E., Anderson, C. L., Gordon, A. M., Mcneil, G. D., \& Keltner, D. (2015). Positive Affect and Markers of Inflammation: Discrete Positive Emotions Predict Lower Levels of Inflammatory Cytokines. Emotion, 15(2), 129-133.

Tong, E. M. W. (2015). Differentiation of 13 positive emotions by appraisals. Cognition \& Emotion, 29, 484-503. 
Treynor, W., Gonzalez, R., \& Nolen-Hoeksema, S. (2003). Rumination reconsidered: A psychometric analysis. Cognitive Therapy and Research, 27, 247-259.

Valdesolo, P., \& Graham, J. (2014). Awe, uncertainty, and agency detection. Psychological Science, 25, 170-178.

Vohs, K. D., \& Schmeichel, B. J. (2003). Self-regulation and the extended now: Controlling the self alters the subjective experience of time. Journal of Personality and Social Psychology, 85, 217-230.

Watson, D., \& Pennebaker, J. W. (1989). Health complaints, stress, and distress: exploring the central role of negative affectivity. Psychological review, 96, 234.

Whitmer, A. J., and Gotlib, I. H. (2013). An attentional scope model of rumination. Psychology Bulletin, 139, 1036-1061.

Widiger, T. A. (2009). Neuroticism. In M. R. Leary \& R. H. Hoyle (Eds.), Handbook of individual differences in social behavior (pp. 129-146). New York, NY: Guilford Press.

Williams, J. M. G., Duggan, D. S., Crane, C., \& Fennell, M. J. (2006). MindfulnessBased cognitive therapy for prevention of recurrence of suicidal behavior. Journal of clinical psychology, 62, 201-210.

Zahn, R., Lythe, K. E., Gethin, J. A., Green, S., William, J. F., Young, A. H., \& Moll, J. (2015). The role of self-blame and worthlessness in the psychopathology of major depressive disorder. Journal of Affective Disorders, 186, 337-341. 


\section{Appendix A \\ The Consent Form/Introduction}

\section{Welcome to the "Nature and cognition" study!}

Thanks for choosing to participate in this study. Please read this consent form carefully before agreeing to participate.

DESCRIPTION: We are researchers at the San Jose State University doing a research study about the effects of nature in cognition/thinking. All data collected in this study are for research purposes only. It is important to the study results that you sit through all the phases of the project. It is particularly important that you pay attention to the short video clip that will be shown to you as it is key to the experiment. Please try to select a quiet place without distraction to participate in the study. Failure to do so might result with exclusion from the experiment and partial compensation. Therefore, you should only participate if you intend to complete all the tasks.

PROCEDURE: You are required to indicate demographic data such as your age, gender, education level and ethnicity. Afterwards you will be presented with instructions and a survey. Next, you will be required to watch a 4-minute video which will be followed by some questions that check whether you have paid attention to the video and can go further with the study. Finally, you will be presented with another survey to complete and will be given instructions on how to enter the code to MTurk so you can be paid. Participation should take about 20-45 minutes of your time. Nevertheless, you can opt out of the study anytime you want but will be compensated only for the tasks you have finished.

RISKS and BENEFITS: The risks to your participation in this online study are those associated with basic computer tasks, including boredom, fatigue, mild stress, etc. There might be personal and mildly sensitive questions that will be asked, however, rest assured that this information will only be used for research purposes and will not identify you in any way.

One benefit to you is the learning experience from participating in a psychology experiment/research study. Another benefit to you may be the experience of pleasant emotions during the video. The benefit to society is the contribution to scientific knowledge and advancement of psychology.

COMPENSATION: The payment will differ depending on the number of the tasks you complete. Although we encourage you to complete the whole study, you can stop at any time. If you complete the first assignment, up to the video task and fail to pay attention to the video, you will be paid only $\$ 0.45$ and will be screened-out after that. The study is only complete if you have completed all the assignments presented to you in which case you would be compensated $\$ 1.25$ and your answers will be included in the study results. 
PLEASE NOTE: This study contains some checks to make sure that participants are finishing the tasks honestly and completely. If you read the instructions and complete the tasks, your HIT will be approved. If you fail these checks, your HIT will be rejected.

CONFIDENTIALITY: Your Mechanical Turk Worker ID will be used to distribute payment to you but will not be stored with your survey responses/data. Please be aware that your MTurk Worker ID can potentially be linked to information about you on your Amazon public profile page, depending on the settings you have for your Amazon profile. We will not be accessing any personally identifying information about you that you may have put on your Amazon public profile page.

Any reports and presentations about the findings from this study will never include your name or any other information that could identify you. Any personally identifying information will be removed to protect your privacy. We may share the data we collect with other researchers doing future studies, but if we do, we will never include any information that could identify you.

SUBJECT'S RIGHTS: Please remember that your participation is voluntary. You may stop participating at any time by closing the browser window or the program to withdraw from the study. Partial data will not be analyzed.

CONTACT: Questions about this research may be addressed to the researcher, Eldita Tarani (Department of Psychology, eldita.tarani@sjsu.edu). Complaints about the research may be presented to Dr. Lynda Heiden (Chair, Department of Psychology, 408-924-5647). For questions about research subjects' rights or to report researchrelated injuries contact Dr. Pamela Stacks (Associate Vice President, Office of Research, 408-924-2479).

Please print or note down this information for your records.

\section{AGREEMENT TO PARTICPATE}

By clicking submit, you indicate that you are at least 18 years old, understand this consent form, and you agree to participate in this online research study. It is implied that you have read the information above about the research, your rights as a participant, and give your voluntary consent.
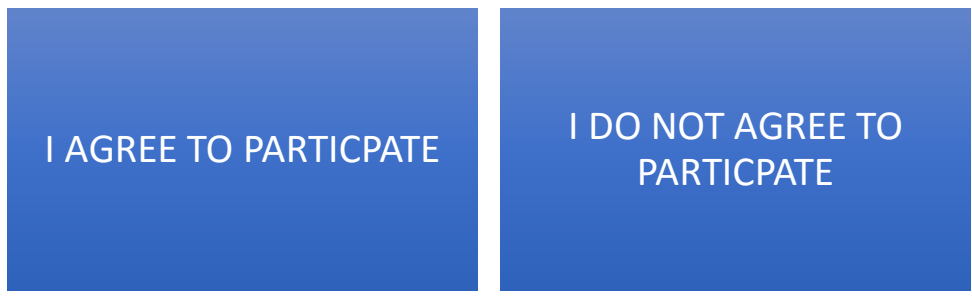


\section{Appendix B \\ DASS-21 Item}

Next, please read each statement and rate it with one of the following values: $0,1,2$ or 3 which indicates how much the statement applied to you over the past week.

There are no right or wrong answers. Do not spend too much time on any statement. When asked about Michael Jackson below, just answer " 0 ".

Click on the value that applies to you mostly based on this rating scale:

0 Did not apply to me at all

1 Applied to me to some degree, or some of the time

2 Applied to me to a considerable degree, or a good part of time

3 Applied to me very much, or most of the time

1 I found it hard to wind down

2 I was aware of dryness of my mouth

$\begin{array}{llll}0 & 1 & 2 & 3\end{array}$

3 I couldn't seem to experience any positive feeling at all

$\begin{array}{llll}0 & 1 & 2 & 3\end{array}$

4 I experienced breathing difficulty (eg, excessively rapid

$\begin{array}{llll}0 & 1 & 2 & 3\end{array}$ breathing, breathlessness in the absence of physical exertion)

5 I found it difficult to work up the initiative to do things

6 I tended to over-react to situations

7 I experienced trembling (eg, in the hands)

$\begin{array}{llll}0 & 1 & 2 & 3\end{array}$

$8 \quad$ I tended to over-react to situations

9 I felt that I was using a lot of nervous energy

10 I was worried about situations in which I might panic and make a fool of myself

11 I felt that I had nothing to look forward to

12 I found myself getting agitated

13 What about Michael Jackson (just click 0 here)

14 I found it difficult to relax

15 I felt down-hearted and blue

16 I was intolerant of anything that kept me from getting on with what I was doing

17 I felt I was close to panic

$\begin{array}{llll}0 & 1 & 2 & 3\end{array}$

$\begin{array}{llll}0 & 1 & 2 & 3\end{array}$

$\begin{array}{llll}0 & 1 & 2 & 3\end{array}$

$\begin{array}{llll}0 & 1 & 2 & 3\end{array}$

$\begin{array}{llll}0 & 1 & 2 & 3\end{array}$

$\begin{array}{llll}0 & 1 & 2 & 3\end{array}$

$\begin{array}{llll}0 & 1 & 2 & 3\end{array}$

$\begin{array}{llll}0 & 1 & 2 & 3\end{array}$

$\begin{array}{llll}0 & 1 & 2 & 3\end{array}$

$\begin{array}{llll}0 & 1 & 2 & 3\end{array}$

$\begin{array}{llll}0 & 1 & 2 & 3\end{array}$

$\begin{array}{llll}0 & 1 & 2 & 3\end{array}$

$\begin{array}{llll}0 & 1 & 2 & 3\end{array}$ 
18 I was unable to become enthusiastic about anything

$\begin{array}{llll}0 & 1 & 2 & 3 \\ 0 & 1 & 2 & 3 \\ 0 & 1 & 2 & 3\end{array}$

20 I felt I wasn't worth much as a person

21 I was aware of the action of my heart in the absence of $\begin{array}{llll}0 & 1 & 2 & 3\end{array}$ physical exertion (eg, sense of heart rate increase, heart missing a beat)

22 I felt scared without any good reason

$\begin{array}{llll}0 & 1 & 2 & 3\end{array}$

23 I felt that life was meaningless

$\begin{array}{llll}0 & 1 & 2 & 3\end{array}$




\section{Appendix C}

\section{BFI-10 Items}

Next, please answer how well do the following statements describe your personality? Please choose one of the options for each question below:

\begin{tabular}{|l|c|c|c|c|c|}
\hline $\begin{array}{l}\text { I see myself as someone } \\
\text { who: }\end{array}$ & $\begin{array}{l}\text { Disagree } \\
\text { strongly }\end{array}$ & $\begin{array}{l}\text { Disagree } \\
\text { a little }\end{array}$ & $\begin{array}{l}\text { Neither } \\
\text { agree } \\
\text { nor } \\
\text { disagree }\end{array}$ & $\begin{array}{c}\text { Agree } \\
\text { a little }\end{array}$ & $\begin{array}{l}\text { Agree } \\
\text { strongly }\end{array}$ \\
\hline $\begin{array}{l}\text { I see myself as someone } \\
\text { who is reserved }\end{array}$ & $(1)$ & $(2)$ & $(3)$ & $(4)$ & $(5)$ \\
\hline $\begin{array}{l}\text { I see myself as someone } \\
\text { who is generally trusting }\end{array}$ & $(1)$ & $(2)$ & $(3)$ & $(4)$ & $(5)$ \\
\hline $\begin{array}{l}\text { I see myself as someone } \\
\text { who tends to be lazy }\end{array}$ & $(1)$ & $(2)$ & $(3)$ & $(4)$ & $(5)$ \\
\hline $\begin{array}{l}\text { I see myself as someone } \\
\text { who is relaxed, handles } \\
\text { stress well }\end{array}$ & $(1)$ & $(2)$ & $(3)$ & $(4)$ & $(5)$ \\
\hline $\begin{array}{l}\text { I see myself as someone } \\
\text { who has few artistic } \\
\text { interests }\end{array}$ & $(1)$ & $(2)$ & $(3)$ & $(4)$ & $(5)$ \\
\hline $\begin{array}{l}\text { I see myself as someone } \\
\text { who is outgoing, sociable }\end{array}$ & $(1)$ & $(2)$ & $(3)$ & $(4)$ & $(5)$ \\
\hline $\begin{array}{l}\text { I see myself as someone } \\
\text { who tends to find faults } \\
\text { with others }\end{array}$ & $(1)$ & $(2)$ & $(3)$ & $(4)$ & $(5)$ \\
\hline $\begin{array}{l}\text { I see myself as someone } \\
\text { who does a thorough job }\end{array}$ & $(1)$ & $(2)$ & $(3)$ & $(4)$ & $(5)$ \\
\hline $\begin{array}{l}\text { I see myself as someone } \\
\text { who gets nervous easily }\end{array}$ & $(1)$ & $(2)$ & $(3)$ & $(4)$ & $(5)$ \\
\hline $\begin{array}{l}\text { I see myself as someone } \\
\text { who has an active } \\
\text { imagination }\end{array}$ & $(1)$ & $(2)$ & $(3)$ & $(4)$ & $(5)$ \\
\hline
\end{tabular}




\section{Appendix D \\ Awe Video, Instructions and IMC's}

Next, please watch a 4-minute video. It is particularly important that you give your undivided attention to the video for this experiment. This means uninterrupted watching of the video on a maximized full-screen, with audio available (speakers will do but preferably you would use headphones for the full experience). Finally, make sure to be in a quiet room with no distractions please!

IMPORTANT! After you have watched it, we will ask a few questions to check and make sure that you have maintained attention and not ignored it. Note that these questions are not designed to trick you or test you on the content of the video but only to check that you watched the video rather than did something during this time. If you don't pass these questions you will not be able to continue with the study but will be paid for the part you already completed.

[A clip containing a compilation of scenes from the BBC's Planet Earth is automatically played for a duration of 4 minutes and 40 seconds, via a YouTube standard license live link]

[The questions appeared after the video has played]

\section{Please answer:}

Now please answer the following questions:

1. Was the song you heard in this video in English? Yes

2. Did you see any humans in this video? Yes No

3. Did you see any animals in this video? Yes

No

4. Does this video end with footage of a talking robot? Yes

No 


\section{Appendix E \\ Amusement Video, Instructions and IMC's}

Next, please watch a 4-minute video. It is particularly important that you give your undivided attention to the video for this experiment. This means uninterrupted watching of the video on a maximized full-screen, with audio available (speakers will do but preferably you would use headphones for the full experience). Finally, make sure to be in a quiet room with no distractions please!

IMPORTANT! After you have watched it, we will ask a few questions to check and make sure that you have maintained attention and not ignored it. Note that these questions are not designed to trick you or test you on the content of the video but only to check that you watched the video rather than did something during this time. If you don't pass these questions you will not be able to continue with the study but will be paid for the part you already completed.

[A clip containing a compilation of funny sketches from the BBC's Walk on the Wild Side is automatically played for a duration of 4 minutes and 40 seconds, via a YouTube standard license live link]

[These questions appeared after the video has played]

Now please answer the following questions:

In this video, did you observe two pandas conversing?

1. What did the primate's scene resemble? Yes__ No

2. Was there a dance scene between two animals in this video? Yes No

3. Did you see any human's in this video? Yes

4. Were the monkey's playing dentist? Yes No No 


\section{Appendix F \\ Emotion Manipulation Check}

By using this rating scale, please answer the following questions that relate to the video:

$0=$ Not at all

$1=$ Slightly

$2=$ Somewhat

$3=$ Moderately

$4=$ Much

$5=$ Very much

$6=$ Extremely

$7=$ Utmost

1. How much awe did you experience while watching this video (feelings of overwhelming respect, wonder, admiration and sense of depth)?

2. How much amusement did you experience while watching this video?

3. To what extent were the images awe-inspiring to you?

4. To what extent did the images challenge your current frame of knowledge?

5. To what extent did this video make you feel like there is something greater out there?

6. To what extent do you feel that you are a part of something bigger?

7. Does this video make you feel awe-struck?

- Yes

- No 


\section{Appendix G \\ The State/Trait Hopelessness Scale}

Please read the following questions and rate them accordingly

Note: There are two time periods you should answer about. First rate the questions considering:

Strongly Disagree / Disagree / Agree / Strongly Agree

Today...

- It is difficult for me to imagine my future

- I believe I cannot make a difference

- I believe that things will improve

- I believe I am powerless to change my future

- I see my future as gloomy

- I believe I will accomplish what I set out to do

- Attention check: Just choose "Disagree" here

- I believe I can help improve things

- I feel giving up would be easier

- I believe I can overcome obstacles

- Things do not work out as I would like

Now please rate the questions considering how it is:

Typically...

- Things do not work out as I would like

- I believe I can overcome obstacles

- I see myself as fortunate

- I see my future as gloomy

- Negative things seem to happen to me

- It is difficult for me to imagine my future

- I believe I can help improve things

- I feel giving up would be easier

- I believe I will accomplish what I set out to do

- I believe that things will improve

- I believe I cannot make a difference

- I doubt that anything is worthwhile

- I believe I am powerless to change my future 


\section{Appendix H \\ Ruminative Response Scale}

And the last set of questions:

People think and do many different things when they feel sad, down or blue. Please read each of the items below and indicate whether you almost never, sometimes, often, or almost always think or do each one when you feel down, sad, or blue. Please indicate what you generally do, not what you think you should do.

Do you:

1 almost never 2 sometimes 3 often 4 almost always

- Think about how alone you feel

- Think "I won't be able to do my job if I don't snap out of this"

- Think about your feelings of fatigue and achiness

- Think about how hard it is to concentrate

- Think "What am I doing to deserve this?"

- Think about how passive and unmotivated you feel.

- Analyze recent events to try to understand why you are depressed

- Think about how you don't seem to feel anything anymore

- Think "Why can't I get going?"

- Think "Why do I always react this way?"

- Go away by yourself and think about why you feel this way

- Write down what you are thinking about and analyze it

- Think about a recent situation, wishing it had gone better

- Think "I won't be able to concentrate if I keep feeling this way."

- Think "Why do I have problems other people don't have?"

- Think "Why can't I handle things better?"

- Think about how sad you feel.

- Think about all your shortcomings, failings, faults, mistakes

- Think about how you don't feel up to doing anything

- Analyze your personality to try to understand why you are depressed

- Please select the option "Almost Always" here:

- Go someplace alone to think about your feelings

- Think about how angry you are with yourself 


\section{APPENDIX I \\ The Demographic Questionnaire}

Please answer the following questions per the instructions

1. How old are you?

2. Please enter your MTurk worker ID which we will use to review and approve your HIT at the end:

3. Please indicate the gender you identify with (choose):

Male Female

4. What ethnicity do you identify with?

White

Hispanic or Latino

Black or African American

Native American or American Indian

Asian / Pacific Islander

Other

5. What is the highest level of school you have completed or the highest degree you have received

- Less than high school degree

- High school graduate (high school diploma or equivalent including GED)

- Some college but no degree

- Associate degree in college (2-year)

- Bachelor's degree in college (4-year)

- Master's degree

- Doctoral degree

- Professional degree (JD, MD)

6. Which statement best describes your current employment status?

- $\quad$ Working for wages as (please specify your job):

- Self-employed (please specify your job)

- Student

- Out of work and looking for work

- Out of work but not currently looking for work

- Stay at home parent

- Retired

- Not able to work (disabled) 
7. How much time do you usually spend in nature? Please slide the blue dot to the point that it matches your answer.

1 - Very little (e.g. less than once a month)

7 - Very much (e.g. at least once a day)

Time spent on nature $0-1-2-3-4-5-6-7$ 


\section{Appendix J \\ Conclusion of the survey and payment instructions}

Thank you for participating in this study!

ATTENTION, please go to the next page to get the unique code which you should copy and paste to the MTurk page to receive your payment. Make sure your browser allows pop up's.

As advised in the consent form, you can reach out the contacts listed there at any time, such as the study coordinator (Eldita.tarani@sjsu.edu). Also, if for any reason, you are feeling distressed after this experiment, please use the emotional support resources available to you such as:

- The 24/7 Crisis Hotline Help: http://crisiscallcenter.org/get-help-247/, by calling (775) 784-8090 from anywhere in the United States or

- The NDMDA Depression Hotline - Support Group: 1-800-826-3632.

Click next! 